\author{
Universidade de São Paulo \\ Instituto de Química de São Carlos
}

Debora Heloisa Capella Salmazo

\title{
Sobre a interação em circuito aberto entre metanol ou etanol e superfícies oxidadas de paládio
}

São Carlos

2013 


\section{Debora Heloisa Capella Salmazo}

Sobre a interação em circuito aberto entre metanol ou etanol e superfícies oxidadas de paládio

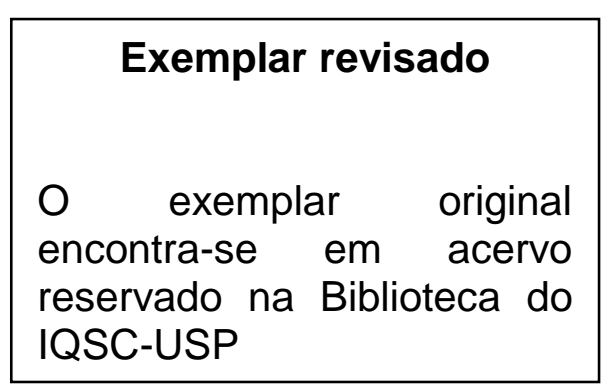

Dissertação apresentada ao Instituto de Química de São Carlos como parte dos requisitos para obtenção do titulo de mestre em ciências.

Área de Concentração: Físico-Química Orientador: Prof. Dr. Hamilton Varela

São Carlos 2013 
"Dedico este trabalho aos meus pais, Emília e Urbano, e meu irmão, João pelo apoio, incentivo e valores. Não há nenhuma palavra que possa expressar minha gratidão." 


\section{Agradecimentos}

Ao professor Dr. Hamilton Varela pelo total apoio, confiança e paciência.

À minha família, em especial, meus pais pelo apoio incondicional.

Aos colegas de laboratório: Andressa Mota, Cristiane Oliveira, Eduardo Machado, Paulo Nogueira, Emerson Bosqueto, Graziela Ferreira, Marcelo Delmonte, Melke Nascimento, Murilo Cabral, Natalia Lussari, Nickson Perini, pelas discussões e o ambiente propício ao desenvolvimento deste trabalho.

Ao CNPQ (processo \# 160 434/2011-4) pela bolsa de estudos concedida e à FAPESP pelo suporte financeiro ao Grupo de Eletroquímica do IQSC/USP. 
"Embora ninguém possa voltar atrás e fazer um novo começo... Qualquer um pode começar agora e fazer um novo fim." Chico Xavier 


\section{Resumo}

SALMAZO, Debora Heloisa Capella. Sobre a interação em circuito aberto entre metanol ou etanol e superfícies oxidadas de paládio. 2013. Instituto de Química de São Carlos, Universidade de São Paulo.

Um dos problemas que contribui para a diminuição do desempenho de células a combustível de membrana trocadora de prótons é o cruzamento de combustível do compartimento anódico para o catódico. Um método de avaliar o contato do combustível anódico com o cátodo consiste da exposição do catalisador oxidado à molécula de interesse, em condições de circuito aberto. Do ponto de vista fundamental, a análise desses transientes de circuito aberto pode fornecer informações importantes acerca do mecanismo reacional associado. São apresentados nessa Dissertação, resultados da interação entre metanol ou etanol e superfícies oxidadas de paládio, em meio alcalino. Entre os parâmetros investigados, maior ênfase foi dada ao efeito da natureza do cátion alcalino presente no eletrólito. Observou-se que a presença de $\mathrm{Li}^{+}$ou $\mathrm{K}^{+}$no eletrólito influencia desde a quantidade de óxido formada, até o tempo requerido para a redução desses óxidos pela molécula orgânico dissolvida. A natureza do composto orgânico presente também exerce diferenças consideráveis no transiente de circuito aberto. Finalmente, foram propostos esquemas reacionais para representar a interação de circuito aberto com o metanol e etanol. Em ambos os casos, os mecanismos incluem a produção auto-catalítica de sítios livres de paládio.

Palavras-chave: transiente de circuito aberto, paládio, cátions alcalinos, metanol, etanol. 


\begin{abstract}
SALMAZO, Debora Heloisa Capella. On the open circuit interaction between methanol or ethanol and palladium oxidized surfaces. 2013. Instituto de Química de São Carlos, Universidade de São Paulo.

One of the problems that contributes to the performance decreasing observed in proton exchange membranes is the fuel crossover from the anodic to the cathodic compartment. A method to evaluate the contact of the anodic fuel with the cathode consists of exposing the oxidized catalyst to the molecule of interest under open circuit conditions. From the fundamental point of view, the analysis of the open circuit transients may provide relevant information on the associated reaction mechanism. In this Dissertation, results of the open circuit interaction between methanol or ethanol with oxidized palladium surfaces, in alkaline media, are presented. Among the distinct investigated parameters, emphasis will be put on the effect of the nature of the alkali cation present in the electrolyte. It was observed that the presence of $\mathrm{Li}^{+}$or $\mathrm{K}^{+}$influences several aspects, from the amount of oxide formed to the time needed for the reduction of the oxide by the dissolved organic molecules. The identity of the dissolved organic molecule also exerts marked influence on the open circuit transients. Finally, two reaction schemes for the open circuit interaction with methanol or ethanol were proposed. In both cases, the mechanisms include the autocatalytic production of free palladium sites.
\end{abstract}

Keywords: open circuit transients, palladium, alkali cations, methanol, ethanol. 


\section{Sumário}

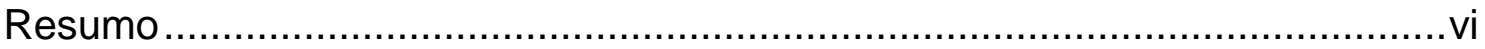

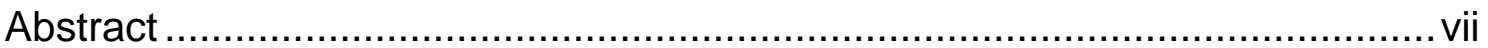

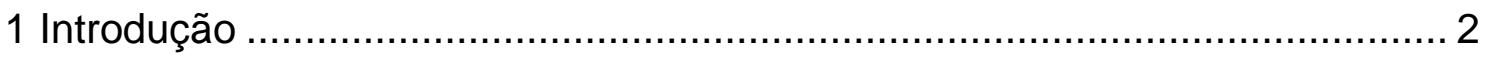

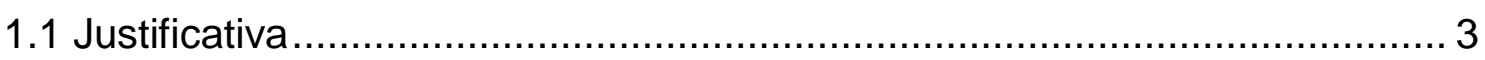

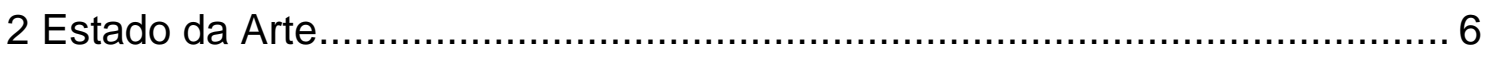

2.1 Interação entre cátions alcalinos e a superfície do catalisador .................... 6

2.2 Transientes de circuito aberto ........................................................... 8

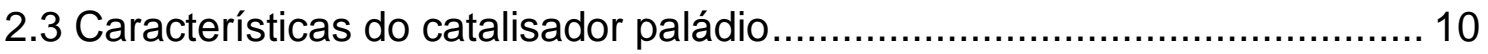

2.3.1 Produtos formados durante a dissociação e eletro-oxidação do metanol em Pd em meio alcalino ........................................................................ 13

2.3.2 Produtos formados durante a dissociação e eletro-oxidação do etanol em Pd em meio alcalino............................................................................. 14

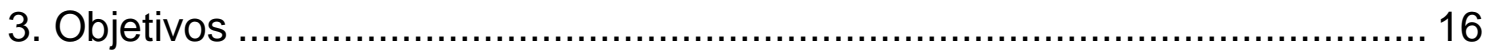

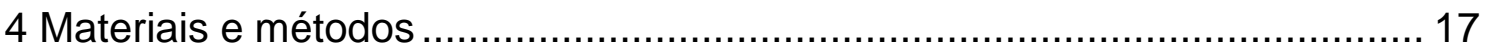

4.1 Sistema eletroquímico convencional ................................................... 17

4.2 Transientes circuito aberto seção 5.2.1 ……...................................... 18

4.2 Transientes de circuito aberto e varredura rápida .................................... 18

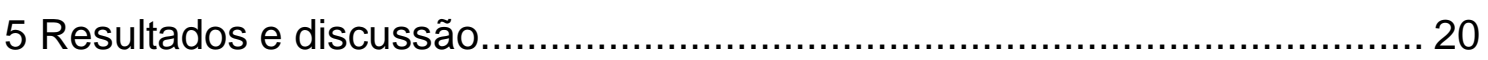

5.1 Influência de cátions alcalinos na eletro-oxidação de metanol e etanol em

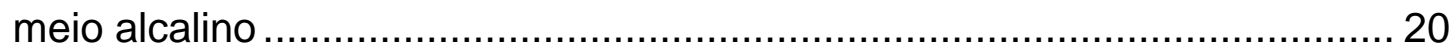

5.2 Transientes de circuito aberto em modo estacionário ............................... 22

5.2.1 Escolha das condições experimentais................................................. 22

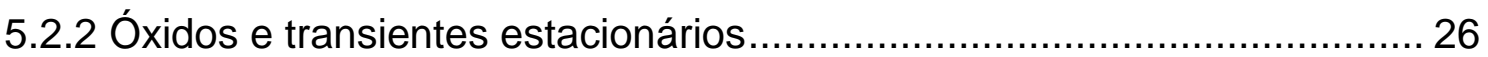

5.3 Transientes de circuito aberto em rotação …………............................... 29

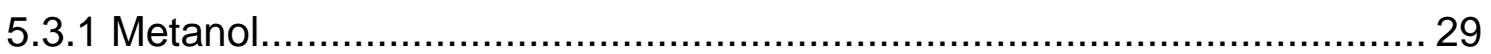

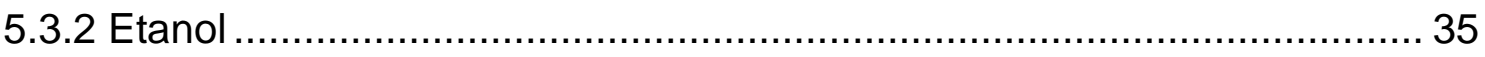

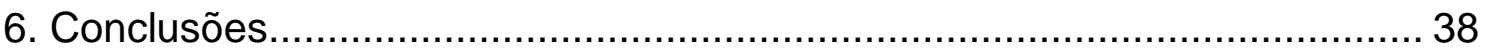

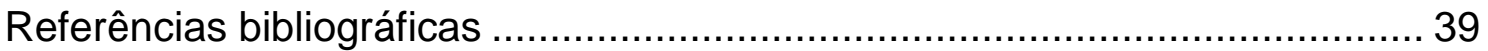

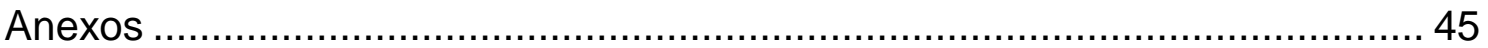




\section{Lista de ilustrações}

Figura 1: Séries temporais de potencial durante a eletro-oxidação de ácido fórmico sobre paládio: tempo de indução $(\mathrm{Pi})$, período sem agitação $(\mathrm{Pa})$ e período com agitação $(\mathrm{Pb})$.

Figura 2: Representação da (a) dupla camada elétrica e (b) variações do potencial ao longo da dupla camada elétrica.

Figura 3: Representação esquemática das diferentes interações entre cátions com pequeno (superior) e grande (inferior) raios em superfície polarizada

Figura 4: Voltamograma cíclico a $100 \mathrm{mVs}^{-1}$ em $\mathrm{KOH}$. 10

Figura 5: Esquema reacional da eletro-oxidação de metanol em superfície de paládio.

Figura 6: Esquema da eletro-oxidação do etanol em paládio. As barreiras energéticas são dadas ( $\mathrm{kcal} \mathrm{mol}^{-1}$ ) e as constantes de velocidade em $\mathrm{s}^{-1}$ a $300 \mathrm{~K}$. Valores calculados. Sendo a linha contínua a rota preferencial.

Figura 7: Voltamograma cíclico em paládio policristalino a $100 \mathrm{mVs}^{-1}$ em dois eletrólitos diferentes: hidróxido de lítio (linha vermelha) e hidróxido de potássio (linha preta).

Figura 8: Voltamogramas ciclicos a $100 \mathrm{mVs}^{-1}$ em Pd policristalino em dois eletrólitos diferentes $1 \mathrm{molL}^{-1}$ (a) $0,250 \mathrm{molL}^{-1}$ de metanol e (b) $0,250 \mathrm{molL}^{-1}$ de etanol. 22

Figura 9: Transientes de circuito aberto em diferentes tempos de polarização 23

Figura 10 : Transientes de circuito aberto em diferentes concentrações de $1 \mathrm{molL}^{-1}$ de $\mathrm{KOH}$ sobre paládio. (a) 100 segundos e (b) 700 segundos.

Figura 11: Transientes de circuito aberto $0,250 \mathrm{molL}^{-1}$ de metanol (a) $1 \mathrm{molL}^{-1}$ de $\mathrm{LiOH}$ e (b) $1 \mathrm{molL}^{-1}$ de $\mathrm{KOH}$ com tempo de polarização de 700 segundos. 25

Figura 12: Esquema representativo das etapas reacionais 26

Figura 13: Transientes de circuito aberto em $1 \mathrm{molL}^{-1}$ de $\mathrm{LiOH}$ ou KOH (a) $0,250 \mathrm{molL}^{-1}$ de metanol e (b) 0,250 $\mathrm{molL}^{-1}$ etanol. Tempo de polarização de $500 \mathrm{~s}$.

Figura 14: Transientes de circuito aberto de $0,250 \mathrm{molL}^{-1}$ de metanol em paládio policristalino em diferentes velocidades (a) $\mathrm{LiOH} 1 \mathrm{molL}^{-1}$ (b) $\mathrm{KOH} 1 \mathrm{molL}^{-1}$.................. 30

Figura 15: Variação temporal dos transientes de circuito aberto de metanol $0,250 \mathrm{molL}$ ${ }^{1}$ em função da rotação em dois eletrólitos: hidróxido de lítio e hidróxido de potássio. 33

Figura 16: Rotação em função do potencial para dois eletrólitos: hidróxido de lítio e hidróxido de potássio. 34 
Figura 17: Transientes de circuito aberto de $0,250 \mathrm{molL}^{-1}$ etanol em paládio policristalino em diferentes velocidades de rotação (a) $\mathrm{LiOH} 1 \mathrm{molL}^{-1}$ (b) $\mathrm{KOH} 1 \mathrm{molL}^{-1}$ 


\section{Lista de Tabelas}

Tabela 1: Quantidade de óxido em diferentes sistemas 27 


\section{Introdução}

Nas últimas décadas o estudo e a aplicação de álcoois como o metanol e etanol vêm despertando o interesse em dispositivos conversores de energia química em elétrica como células a combustível. (1) (2) Nesse sentido, o metanol é um dos compostos mais estudados. (3) (4). Todavia, por não ser um combustível renovável, tem-se buscado outros compostos mais adequados, do ponto de vista ambiental. Neste ponto, o etanol tem se mostrado um substituto em potencial. (5) As células a combustível que utilizam álcoois diretamente são chamadas de Direct Alcohol Fuel Cells (DAFCs).

Iwasita, (6) em seu artigo de revisão sobre a eletro-catálise de metanol em platina afirma que, além do material do eletrodo e das condições da superfície, os principais fatores que interferem na reação de eletro-oxidação do metanol são a temperatura, a concentração do álcool, a rugosidade do eletrodo e o tempo de uso da superfície. Como outras moléculas pequenas, seu mecanismo é dual e inclui a formação de monóxido de carbono, formaldeído e metil-formato.

Camara (7) mostrou que há uma dependência entre a quantidade de etanol utilizada na catálise e os produtos formados. Tanto o monóxido de carbono quanto o ácido não são formados apreciavelmente em concentrações superiores a $0,1 \mathrm{~mol} \mathrm{~L}^{-1}$ devido à redução de sítios livres na superfície da platina e o acetaldeído só é detectado em concentrações inferiores a esta.

Grande parte dos estudos nessa direção é realizada em superfície à base de platina, por apresentar melhor desempenho. No entanto, o seu uso em grande escala é dificultado devido ao preço no mercado internacional. Além disso, quando a platina é usada em temperatura ambiente, como ânodo, é rapidamente envenenada por monóxido de carbono originado da oxidação de álcoois e da reforma do gás hidrogênio. $\mathrm{Na}$ utilização como cátodo não apresenta atividade satisfatória na reação de redução de oxigênio. Assim, outros materiais têm sido estudados na tentativa de melhorar a operação de células a combustível. (8) (9) Dentre eles, um dos quais que apresenta maior potencial é o paládio que está presente no mesmo grupo da tabela periódica da 
platina e apresenta algumas características comuns como raio atômico, empacotamento cristalográfico e tamanho de partícula semelhante. (10)

A superfície de paládio é relativamente inativa em meio ácido para eletro-oxidação de álcoois pequenos (11). Biegler mostrou que a eletrooxidação de metanol, em superfícies bi-metálicas paládio - platina é prejudicada a pHs baixos se adicionado mais de $33 \%$ do primeiro metal (12). Porém, no caso do etanol existe um melhor desempenho do catalisador quando as proporções são de 1:1 (platina-paládio).

O acréscimo da atividade catalítica em meio alcalino é atribuído a competição que ocorre durante a adsorção entre espécies oxigenadas e os ânions presentes na solução (13). Atualmente, o álcool que apresenta melhor atividade catalítica em células a combustível a base de paládio é o 2-propanol (14) e os piores são o metanol e o etileno glicol na mesma faixa de $\mathrm{pH}$ (15) (16).

A eletro-oxidação oscilatória de moléculas orgânicas pequenas sobre platina tem sido amplamente estudada nos últimos anos, principalmente em meio ácido. Varela e colaboradores (17) (18) estudaram o efeito da temperatura na eletro-oxidação oscilatória de metanol e ácido fórmico em meio ácido. No caso do ácido fórmico foi observado que a natureza das oscilações dependem da corrente aplicada. Quando os valores de corrente aplicada são baixos existe um aumento da amplitude e do período com o aumento da temperatura. O mesmo fenômeno não é observado quando a corrente aplicada é alta. Desse modo, tanto a amplitude quanto o período não variam com a temperatura. O primeiro estudo com moléculas de três carbonos com vistas em instabilidades foi realizado com glicerol (19). Observou-se que em meio ácido o comportamento oscilatório é regular com amplitudes médias e grandes. E não são afetadas pela concentração do álcool. Em contraste, em meio alcalino, as oscilações se apresentam em vários tipos, desde periódicas até complexas. E dependem da concentração de glicerol. Mostrando que o acréscimo de pH favorece a obtenção de séries mais complexas. A adição de estanho a superfície de platina na eletro-oxidação oscilatória do ácido fórmico ocasionou uma diminuição no potencial do eletrodo durante as oscilações e com isso aumentou-se o tempo em que o sistema apresentou instabilidades. Indicando 
que sistemas intermetálicos podem ser mais eficientes para algumas aplicações específicas. (20).

Tian e Conway (21) mostraram a existência de oscilações durante a eletro-oxidação de ácido fórmico sobre paládio em meio ácido, e exploraram o efeito do transporte de massa. Alguns resultados típicos com este sistema são ilustrados na Figura 1 (22). Em linhas gerais, nota-se que o padrão oscilatório é diferente do observado para o ácido fórmico sobre platina (18). Um longo tempo de indução é mostrado na região $\mathrm{Pi}$, com cerca de 3800 segundos. $\mathrm{Na}$ região $\mathrm{Pa}$ são mostradas oscilações sem agitação com período de 18 minutos e quando há agitação o tempo é de apenas 9 minutos. Isto significa que a etapa lenta de envenenamento da superfície é acelerada por meio do aumento da concentração de ácido fórmico no plano reacional, como resultado do transporte de massa facilitado pela agitação da solução.

Figura 1: Série temporal de potencial durante a eletro-oxidação de ácido fórmico sobre paládio: tempo de indução $(\mathrm{Pi})$, período sem agitação $(\mathrm{Pa})$ e período com agitação $(\mathrm{Pb})$.

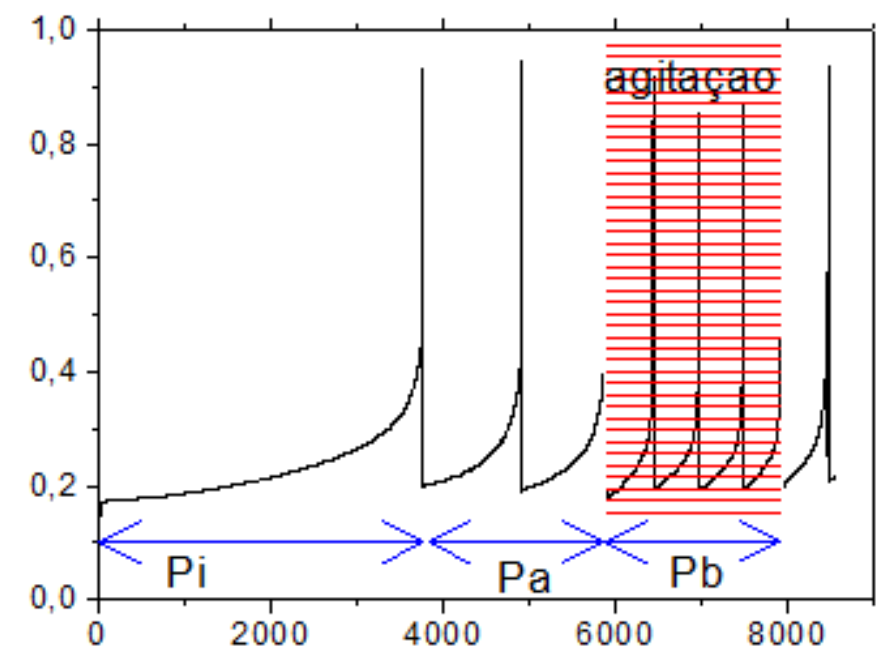

Tempo/s

Fonte: Mota, A.; Salmazo, D. ; Varela. H. ; Gonzalez, E. R.; Eiswirth, M. Eletro-oxidação oscilatória de ácido Fórmico sobre Paládio: uma visão cinética e mecanística, Bento Gonçalves, CD XXVIII Sibee, 2011.

Motivados pelos relatos da literatura e pelos resultados iniciais apresentados na Figura 1, decidiu-se estudar as instabilidades dinâmicas 
associadas à interação entre metanol e etanol sobre superfícies oxidadas de paládio.

No caso do paládio a atividade catalítica de oxidação e dissociação de álcoois é mais eficiente em meio alcalino que em meio ácido. (1) (23) Deste modo escolheu-se utilizar hidróxidos como eletrólito de suporte e os álcoois metanol e etanol foram escolhidos. Oscilações não foram observadas neste sistema e um estudo de transientes de circuito aberto foi realizado.

Nas próximas seções serão descritas as motivações do trabalho e a revisão bibliográfica dos temas mais relevantes. 


\section{Estado da Arte}

\subsection{Interações entre cátions alcalinos e a superfície do catalisador}

Grande parte dos fenômenos da dupla camada elétrica foi realizada nas décadas de 60-70 em eletrodos de mercúrio. (24) (25) Uma visão esquemática de uma dupla camada elétrica formada na interface sólido/líquido eletrificada é dada na Figura 2 (a). Pode-se observar a existência de um eletrodo positivamente carregado imerso em solução aquosa, representada por círculos azuis. Sendo que cátions têm coloração amarela e ânions laranja. Os cátions, de maneira geral, apresentam raio pequeno e são fortemente solvatados por moléculas de água. Já os ânions, com raios maiores, apresentam uma densidade de carga menor permitindo uma adsorção especifica. Em outras palavras, torna possível uma adsorção direta na superfície do eletrodo.

Figura 2: Representação da (a) dupla camada elétrica e (b) variações do potencial ao longo da dupla camada elétrica.

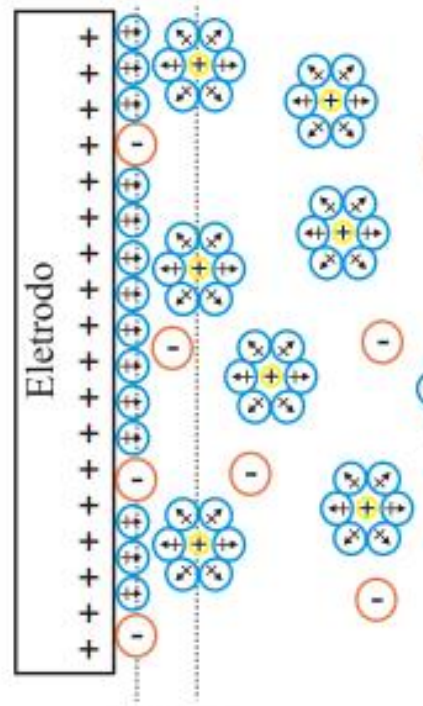

PIH PEH (a)

(b)

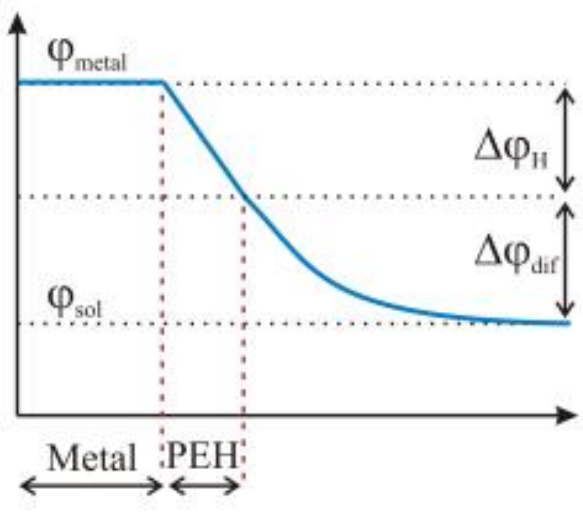

Fonte: Sitta, Elton Fabiano. Efeitos de cátions alcalinos e a cinética complexa durante a eletro-oxidação do etileno glicol. 2012. Tese (Doutorado em Físico Química) - Instituto de Química de São Carlos.

A literatura denomina que o plano que passa no centro dos ânions é o Plano Interno de Helmholtz $(\mathrm{PIH})$ e o que passa pelo centro dos cátions Plano 
Externo de Helmholtz (PEH). Na Figura 2 (b) é mostrado como o potencial varia à medida que se afasta da superfície do metal. Se considerarmos o potencial constante na superfície do eletrodo, a primeira queda é linear próxima ao eletrodo devido à alta adsorção. Após o PEH ocorre uma queda um pouco diferente até atingir o valor do seio da solução. Essa região é comumente divida em duas partes: queda até $\mathrm{PEH}\left(\Delta \varphi_{H}\right)$ e a queda na camada difusora $\left(\Delta \varphi_{\text {dif }}\right)$.

Em um trabalho recente, Markovic e colaboradores mostraram que cátions metálicos hidratados interagem com espécies oxigenadas na superfície de platina causando um grande efeito na eletro-redução do oxigênio, eletrooxidação de hidrogênio e eletro-oxidação de metanol. (26) É possível afirmar que, de modo geral, a energia de solvatação diminui com o aumento do raio do cátion. Essa diferença de interação interfere na forma como o cátion interage com o eletrodo. Para cátions menores, a interação ocorre diretamente entre o cátion e o $\mathrm{PIH}$, isto é resultado da densidade de carga nestes casos ser elevada e o número de moléculas na primeira camada de solvatação ser baixo. Com o aumento do tamanho do cátion, a densidade de carga diminui. Deste modo, a forma de interação é alterada e a adsorção ocorre por meio da camada de solvatação. Na Figura 3 são mostrados de forma esquemática os dois meios de interação. Na parte superior tem-se a interação direta entre o cátion e as moléculas adsorvidas no eletrodo e na parte inferior por meio da camada de solvatação.

Estudos sobre os efeitos de cátions já foram realizados para moléculas com dois e três carbonos. Sitta e colaboradores (26) observaram que o tamanho do cátion influencia a eletro-oxidação do etileno glicol em platina. No sistema com hidróxido de lítio o principal produto formado é o oxalato enquanto que para o hidróxido de potássio é o carbonato. Indicando que a presença de cátions maiores, como no caso do potássio, favorecem a quebra da ligação $C$ C. Isto ocorre devido a maior presença de sítios superficiais livres e com a técnica de FT-IR (Fourier Transform Infrared Spectroscopy) comprovaram que há um aumento na velocidade de reação com o tamanho do cátion, ou seja, a sequência $\mathrm{Li}^{+}<\mathrm{Na}^{+}<\mathrm{K}^{+}$é observada. (27)

A adsorção/dessoção dos cátions e sua interação não covalente com a superfície metálica descrita nos parágrafos anteriores não geram fluxos de 
elétrons na superfície e são denominados não faradáicos. Quando há apenas este tipo de comportamento o conjunto se assemelha ao dos capacitores, em que a corrente é proporcional a velocidade de varredura e em um potencial fixo não há corrente.

Figura 3: Representação esquemática das diferentes interações entre cátions com pequeno (superior) e grande (inferior) raios em superfície polarizada

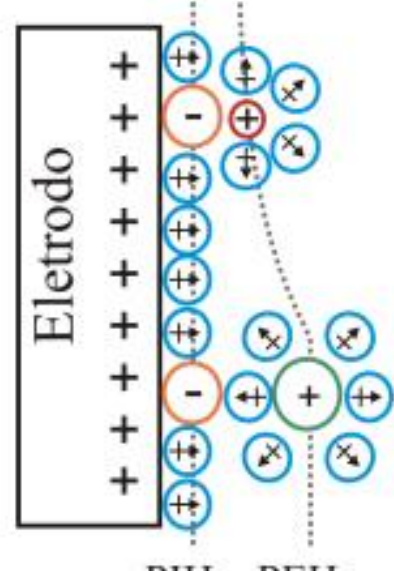

$\mathrm{PIH}$ PEH

Fonte: Sitta, Elton Fabiano. Efeitos de cátions alcalinos e a cinética complexa durante a eletro-oxidação do etileno glicol. 2012. Tese (Doutorado em Físico Química) - Instituto de Química de São Carlos.

\subsection{Transientes de circuito aberto}

As membranas utilizadas nas células a combustível DAFCs (Direct Alcohol Fuel Cells) são otimizadas para conduzir prótons, porém, não são muito eficientes em bloquear a passagem de álcool do ânodo para o cátodo. Esse cruzamento de combustível causa uma diminuição da eficiência global do dispositivo, contribuindo para a limitação atual do seu uso em grande escala (28).

Um dos métodos utilizados para compreender esse fenômeno consiste no estudo da interação das moléculas de álcool com superfícies oxidadas em condições de circuito aberto em células convencionais (configuração de meiacélula). A metodologia consiste em oxidar a superfície em condições potenciostáticas ou galvanostáticas por um período de tempo e depois abrir o circuito do sistema, de forma que a interação entre o combustível e a superfície 
oxidada é monitorada por meio do transiente de potencial em função do tempo. O consumo de óxido ocorre por via química ou pela combinação de reações de oxidação e redução (29) (30).

Podlovchenko et al. (31) (32) (33) estudaram a interação entre vários compostos orgânicos e superfícies oxidadas de platina. O tempo envolvido na reação de consumo de óxido decresce em compostos $\mathrm{HCO}$ em geral do seguinte modo: $\mathrm{CH}_{3} \mathrm{OH}>\mathrm{HCOOH}>\mathrm{HCHO}$, ou seja, a velocidade aumenta de $\mathrm{CH}_{3} \mathrm{OH}$ a $\mathrm{HCHO}$. Estudos com pulsos catódicos foram descritos como muito eficientes para determinação da cobertura de $\mathrm{O}_{\text {ads }}$ e produtos de quimissorção dos compostos HCO.

Sitta e Varela (30) estudaram a interação entre o metanol e superfícies oxidadas de platina utilizando transientes de circuito aberto. Os autores observaram que há dependência entre a quantidade de óxido formado e o tempo de polarização. Maiores tempos de polarização apresentam maiores quantidades de óxido. E o potencial de equilíbrio independe do tempo utilizado. Também foi analisado o efeito dos ânions na formação dos óxidos. Indicando que a presença de espécies mais fortemente adsorvida inibe a formação de óxidos. Sendo que os valores diminuem na seguinte ordem $\mathrm{Cl}^{-}>\mathrm{SO}_{4}^{-2}>\mathrm{ClO}_{4}{ }^{-}$.

Batista e colaboradores (29) utilizaram IR (Infrared Spectroscopy) in situ para estudar os transientes de circuito aberto em platina. Para o caso do metanol observaram que o principal produto formado no início dos transientes era o ácido fórmico e a diminuição do potencial coincide com a formação de $\mathrm{CO}_{2}$. Para o etanol, o principal produto detectado foi o acetaldeído e apenas traços de $\mathrm{CO}$ e $\mathrm{CO}_{2}$ foram observados.

Um dos estudos de transientes de circuito feito por Podlovchenko et al. (34) para metanol em platina mostrou que quando a cobertura por óxido é alta entre 1 e 0,8 monocamada, potenciais entre 1,1 e 0,86 V, o consumo do óxido ocorre por interação direta com o metanol um mecanismo denominado EleyRideal. (35) (36) E em coberturas intermediárias entre 0,8 e 0,2 monocamada, potencial entre 0,86 e 0,68V, o consumo procede por meio do mecanismo chamado de "reações conjugadas" no qual a oxidação do metanol ocorre simultaneamente à redução de óxidos superficiais. 
Nesta seção serão mostradas características que podem influenciar a eletro-oxidação da superfície de paládio tais como tempo de polarização, quantidade, quais compostos são formados em cada potencial, entre outras.

$\mathrm{Na}$ Figura 4 é mostrado o voltamograma cíclico de paládio em $1 \mathrm{~mol} \mathrm{~L}^{-1}$ de $\mathrm{KOH}$. Durante a varredura positiva podem ser observados três picos ou ombros. Eles representam diferentes processos que ocorrem na superfície do metal. O pico I observado entre 0,10 e $0,30 \mathrm{~V}$ representa o processo de absorção e adsorção de hidrogênio na equação [1]. (37) (38)

Figura 4: Voltamograma cíclico a $100 \mathrm{mVs}^{-1} \mathrm{em} \mathrm{KOH}$

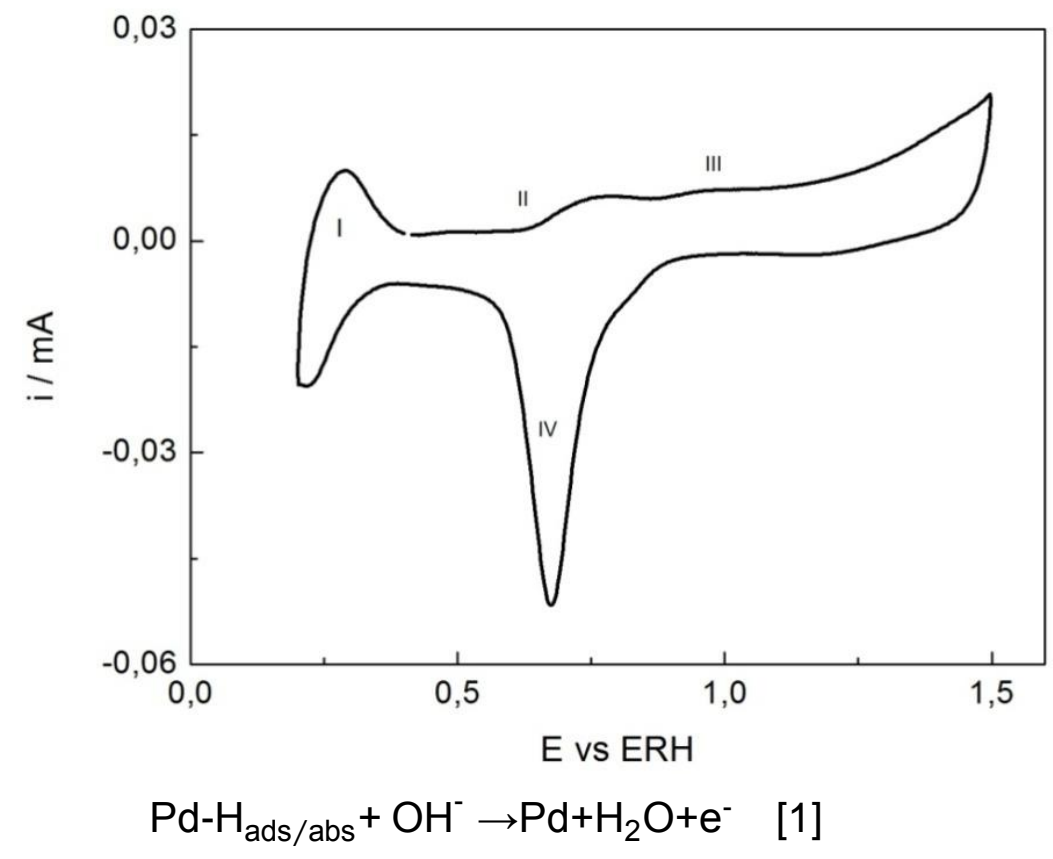

Já o pico III que ocorre acima de $0,90 \mathrm{~V}$ e o pico II pode estar relacionados com a formação de monocamadas de óxido de paládio na superfície do eletrodo. O processo não está totalmente claro, mas tem sido aceito que os íons $\mathrm{OH}^{-}$são quimissorvidos em um estágio inicial da formação dos óxidos e em altos potenciais são transformados em óxidos de maior valência, as equações que descrevem esse processo são descritas abaixo (38) (39). 


$$
\begin{gathered}
\mathrm{Pd}+\mathrm{OH}^{-} \leftrightarrow \mathrm{Pd}-\mathrm{OH}_{\mathrm{ads}}+\mathrm{e}^{-} \\
\mathrm{Pd}-\mathrm{OH}_{\mathrm{ads}}+\mathrm{OH}^{-} \leftrightarrow \mathrm{Pd}-\mathrm{O}+\mathrm{H}_{2} \mathrm{O}+\mathrm{e}^{-} \\
\mathrm{Pd}-\mathrm{OH}_{\mathrm{ads}}+\mathrm{Pd}-\mathrm{OH}_{\mathrm{ads}} \leftrightarrow \mathrm{Pd}-\mathrm{O}+\mathrm{H}_{2} \mathrm{O}
\end{gathered}
$$

O pico IV está associado à redução de $\mathrm{Pd}(\mathrm{II})$ durante a varredura catódica, como mostrado abaixo. (39) (40)

$$
\mathrm{Pd}-\mathrm{O}+\mathrm{H}_{2} \mathrm{O}+2 \mathrm{e}^{-} \leftrightarrow \mathrm{Pd}+2 \mathrm{OH}^{-}[5]
$$

Um dos fatores que influenciam a forma do perfil voltamétrico é a adsorção de hidrogênio na superfície do eletrodo associada a mudanças tridimensionais na estrutura. Podendo ser a quebra de ligações, a formação de hidretos, acumulação de gases de hidrogênio nas lacunas da superfície. (41) É aceito que o potencial de início da eletro-oxidação em paládio seja entre 0,60$0,75 \mathrm{~V}$ vs RHE (42) (43) e esses potenciais decrescem com o aumento do $\mathrm{pH}$ do eletrólito. (44)

Muitos autores sugerem que a formação de $\mathrm{PdOH}_{\text {ads }}$ é a primeira etapa da eletro-oxidação de paládio tanto na presença de eletrólitos ácidos ou básicos. (44) (45) Acredita-se que o $\mathrm{OH}$ origina-se das moléculas de $\mathrm{H}_{2} \mathrm{O}$ no caso eletrólitos ácidos e já para os eletrólitos básicos o $\mathrm{OH}$ provem do íon $\mathrm{OH}^{-}$. Esta proposição está em concordância com o mecanismo de eletro-oxidação da platina proposto por Conway et al. (46) que é adotado para muitos outros metais nobres.

Estudos cinéticos da eletro-oxidação de paládio foram conduzidos por Chierchie et al. (47) sob condições potenciostáticas (1,05-1,65 V vs. NHE) em $0.5 \mathrm{molL}^{-1}$ de ácido perclórico aquoso com o intuito de examinar a formação de multicamadas de óxidos em função de condições experimentais. A quantidade de óxido formado foi expressa como sendo a densidade de carga de óxido ( $\left.q_{\circ x}\right)$ que foi obtida sobre para vários tempos de polarização (tp). Os valores de $q_{\mathrm{ox}}$ foram plotados em função de log tp e uma relação linear é observada onde a espessura da camada varia não mais que duas camadas de PdO.

Já Bolzan et al. (48) utilizaram elipsometria para examinar a espessura da camada de óxido de paládio formado sobre polarização anódica nos 
potencias de 1,90 - 2,06 V em ácido sulfúrico e o ácido perclórico. Eles observaram uma relação logarítmica entre a espessura do óxido e o tempo de polarização para as camadas nas quais as espessuras eram maiores que 10 $\mathrm{nm}$ para $\mathrm{Ep}=1,90 \mathrm{~V}$ e maiores que $20 \mathrm{~nm}$ para $\mathrm{Ep}=2,06 \mathrm{~V}$. Concluíram que $\mathrm{o}$ crescimento de óxido é limitado pela migração de íons.

Outros autores concluíram por intermédio da análise da resposta voltamétrica que a completa formação de uma monocamada de óxido de paládio ocorre 1,45-1,50V vs. RHE. Contudo, outros autores sugerem que a faixa potencial para o crescimento da monocamada de óxido ocorre em 1,1-1,3 V vs. RHE especialmente em eletrólitos básicos. (49) (50)

Também há discrepâncias com relação à natureza do estado de oxidação formado. O principal estado de oxidação relatado é o $\mathrm{Pd}(\mathrm{II})$, porém estado de oxidação $\mathrm{Pd}(\mathrm{IV})$ também já foi relatados na literatura. (47) (51) Os óxidos formados em potenciais inferiores ao $\mathrm{E}_{\mathrm{OER}}^{\circ}$ (monocamada ou a-óxidos) contém principalmente $\mathrm{Pd}(\mathrm{II})$. Isto foi mostrado por análise de XPS (X-ray Photoelectron Spectroscopy). (47) (51) De acordo com o diagrama de Pourbaix para o paládio (52) o potencial padrão do par de redução $\operatorname{Pd}(\mathrm{IV}) / \mathrm{Pd}(\mathrm{II})$ é 1,20 $1,28 \mathrm{~V}$ vs. RHE, enquanto que o potencial padrão para o par $\operatorname{Pd}(\mathrm{IV}) / \operatorname{Pd}(0) 1,47$ $V$ vs. RHE. Como o valor do segundo par de redução é maior que o primeiro par, aparentemente o óxido de $\operatorname{Pd}(\mathrm{IV})$ não deve se formar sobre polarização onde $\mathrm{Ep}<\mathrm{E}_{\text {OER }}^{\circ}$. Contudo, vários autores relataram a formação de óxido de $\mathrm{Pd}(\mathrm{IV})$ nestas condições em prolongados tempos de polarização. (43) (51) (53) (54)

A quantidade de água contida na camada de óxido é um importante aspecto que deve ser levado em consideração, pois determina sua estrutura e atividade. Em relação ao óxido de $\mathrm{Pd}(\mathrm{II})$ eles podem ser anidros (45) (54) ou hidratados, como $\mathrm{Pd}(\mathrm{OH})_{2}, \mathrm{PdO} \cdot \mathrm{H}_{2} \mathrm{O}$ ou $\mathrm{Pd}(\mathrm{OH})_{2} \cdot \mathrm{H}_{2} \mathrm{O}$. E análises de EQCM (Electrochemical Quartz-Crystal Microbalance) comprovam este fato (43).

A natureza do óxido de $\mathrm{Pd}(\mathrm{IV})$ formado em mais potenciais baixos que o $\mathrm{E}_{\text {OER }}^{\circ}$ ainda é pouco entendida e as discrepâncias aparecem devido aos diversos procedimentos para a geração desses óxidos como voltametria cíclica e polarização potenciostática.

Em eletrólitos básicos, o óxido de $\mathrm{Pd}(\mathrm{IV})$ pode ser coberto com uma camada de ânions adsorvidos como $\mathrm{OH}^{-}$, porém com eletrólitos ácidos não se 
observa a formação de óxido de $\operatorname{Pd}(\mathrm{IV})$ (42). É mostrado também que os óxidos formados em meio alcalino são mais estáveis e podem se hidratar formando complexos contendo ânions $\mathrm{OH}^{-}$ou cátions de metais alcalinos. (43).

\subsubsection{Produtos formados durante a dissociação e eletro-oxidação do metanol em Pd em meio alcalino}

A maior parte dos estudos envolvendo a eletro-oxidação de metanol tem-se baseado em sistemas com catalisador de platina em meio ácido. Porém, seu alto custo dificulta 0 uso em grande escala, então o desenvolvimento de um polímero de baixo custo para eletrólito alcalino para sistemas baseados em paládio se faz interessante, uma vez que a eficiência eletrocatalítica é maior com o acréscimo de $\mathrm{pH}$. (1) (23)

A dissociação e eletro-oxidação do metanol em platina em ambos os meios foram estudados por diversas técnicas como DEMS (Differential Electrochemical Mass Spectrometry) e FT-IR (Fourier Transform Infrared Spectroscopy). Por outro lado, reações sobre paládio têm recebido bem menos atenção. Existem, aparentemente, apenas dois trabalhos que utilizam 0 infravermelho para análise dos produtos formados durante a reação de eletrooxidação de metanol. Um de Nishimura et al. (55) e outro de Wen Bin et al. (56).Este último utilizou sistemas com hidrogênio e deutério juntamente com a técnica de ATR-SEIRAS (Surface Enhanced Infra-Red Absorption) para analisar as possíveis rotas de eletro-oxidação do metanol em meio alcalino sobre paládio metálico. No qual mostrou que o álcool pode se dissociar em duas rotas. Na primeira formar $\mathrm{CO}_{\mathrm{ad}}$ em condições de circuito aberto. Este processo se inicia com a quebra da ligação $\mathrm{O}-\mathrm{H}$ seguida pela clivagem das ligações $\mathrm{C}-\mathrm{H}$. Na outra rota o produto final formado é o $\mathrm{CO}_{2}$ ou $\mathrm{CO}_{3}{ }^{2-}$ dependendo da natureza do eletrólito utilizado. $\mathrm{O}$ formiato é considerado como um produto final quando não há a eletro-oxidação completa do metanol na segunda rota. A conclusão deste estudo é que o mecanismo de eletro-oxidação do metanol em paládio é similar ao da platina em meio alcalino. No entanto, ressaltou-se que é necessário um potencial maior para oxidar os intermediários e a velocidade de conversão de formato a $\mathrm{CO}_{2}$ é menor para o caso do paládio, um exemplo de mecanismo pode ser visto na Figura 5. 
Figura 5: Esquema reacional da eletro-oxidação de metanol em superfície de paládio.

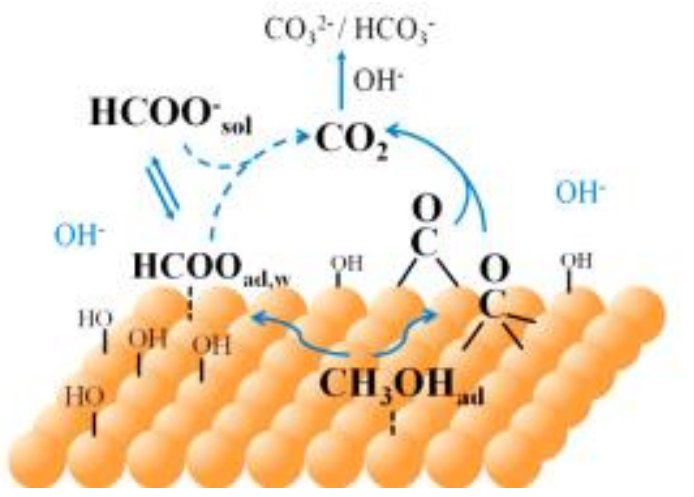

Fonte:Yao-Yue Yang, JieRen, Han-Xuan Zhang, Zhi-You Zhou,Shi-Gang Sun, and Wen-Bin Cai, Infrared Spectroelectrochemical Study of Dissociation and Oxidation of Methanol at a Palladium Electrode in Alkaline Solution, Langmuir, $\mathrm{n}$ 29, p 1709 - 1716, 2013

\subsubsection{Produtos formados durante a dissociação e eletro-oxidação do etanol em Pd em meio alcalino}

Nas últimas décadas tem-se dado enfoque ao estudo de combustíveis não fosseis, principalmente os provenientes da fermentação de biomassa como o etileno-glicol e o etanol. Por apresentar menor toxicidade e ser mais abundantemente obtido, o segundo álcool é utilizado em diversos processos. Uma dificuldade encontrada é a cinética lenta e a dificuldade da quebra da ligação C-C. Assim, é de grande interesse a obtenção de novos catalisadores que aumentem a velocidade de reação de oxidação, facilitem a quebra da ligação C-C e que apresente um baixo custo de fabricação. Entre eles, o paládio apresenta grande potencial (1).

Poucos estudos foram realizados para compreender a eletro-oxidação do etanol em catalisador de paládio em meio alcalino. Fang et al. (57) usaram a espectroscopia de FTIR in situ e demonstraram que o principal produto formado é o acetado e menos de $2,5 \%$ do etanol é convertido a $\mathrm{CO}_{2}$. Este baixo valor está diretamente ligado a não quebra da ligação C-C.

Um estudo teórico, no qual se utilizou DFT (58), sugeriu que o etanol adsorve inicialmente em ponte sobre o sítio e há de-hidrogenação do mesmo com barreira energética de $16,6 \mathrm{kcal} \mathrm{mol}^{-1}$ e com a constante de velocidade 
$3.0 \times 10^{6} \mathrm{~s}^{-1}$. O etóxi formado na primeira etapa pode se de-hidrogenar novamente e formar $\mathrm{CH}_{3} \mathrm{CHO}$. Essa rota é favorecida devido a menor energia envolvida no processo. Neste ponto, descarboxilização é preferencial seguido pela formação de $\mathrm{CH}_{3}$ e $\mathrm{CO}$. A de-hidrogenação é possui menor gasto energético novamente. $\mathrm{E}$ em altas temperaturas pode haver a presença de carbono. Um esquema é mostrado na Figura 6.

Figura 6: Esquema da eletro-oxidação do etanol em paládio. As barreiras energéticas são dadas $\left(\mathrm{kcal} \mathrm{mol}^{-1}\right)$ e as constantes de velocidade $\mathrm{em} \mathrm{s}^{-1}$ a $300 \mathrm{~K}$. Valores calculados. Sendo a linha contínua a rota preferencial.

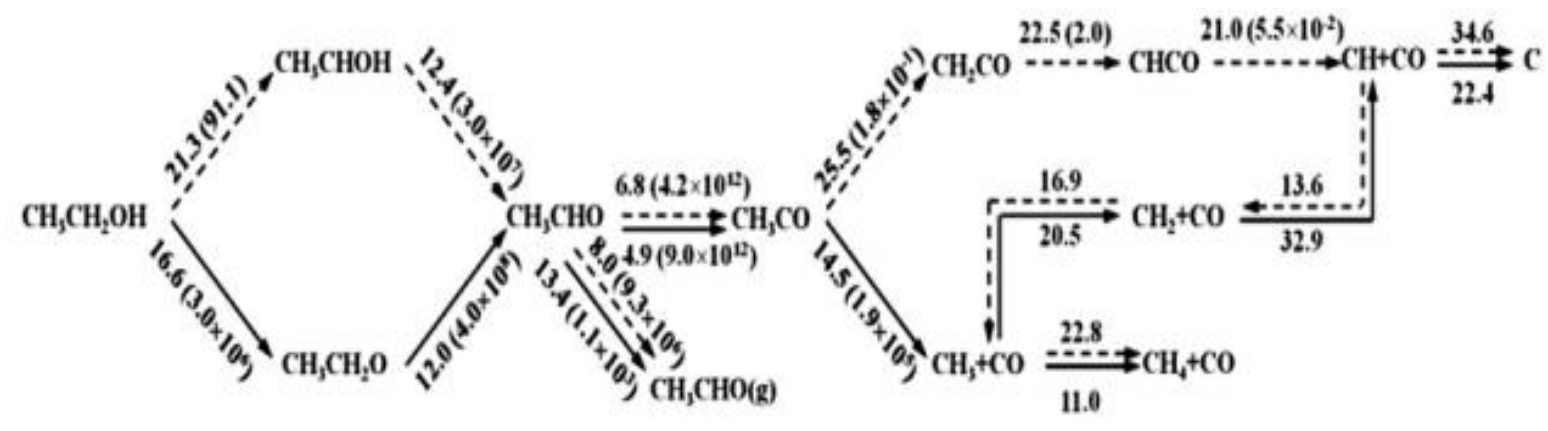

Fonte: Guo, W.; Li, M.; Lu, X.; Zhu, H.; Li, Y.; Li, S.; Zhao, L. Ethanol decomposition on a $\operatorname{Pd}(110)$ surface: a density functional theory investigation, Dalton Transactions, n 42, p 2309 -2018, 2013. 


\section{Objetivos}

O presente trabalho tem como objetivo estudar a interação em circuito aberto entre metanol ou etanol e superfícies oxidadas de paládio, em meio alcalino. O estudo foi feito com base nos efeitos exercidos pelos seguintes parâmetros: (a) transporte de massa, (b) presença dos cátions $\mathrm{Li}^{+}$e $\mathrm{K}^{+}$, e (c) quantidade inicial de óxido. 


\section{Materiais e métodos}

Todos os componentes da célula passaram por um rigoroso procedimento de limpeza, o qual consiste de: (1) banho de solução aquosa alcalina de permanganato de potássio por, pelo menos, 12 horas; (2) banho de solução aquosa ácida de peróxido de hidrogênio $30 \%$ por 30 minutos; (3) aquecimento em água ultrapura até ebulição por 4 vezes.

As soluções foram preparadas com água deionizada (Milli-Q 18,2 $\mathrm{M} \Omega . \mathrm{cm}^{-1}$ ). Foram utilizados dois eletrólitos de suporte com diferentes cátions a $1 \mathrm{molL}^{-1}$ sendo eles: $\mathrm{KOH}$ (Sigma Aldrich, metal grade, 99,99\%) e LiOH (Alfa Aeser 99,995\%). As moléculas orgânicas foram metanol (J. T. Backer 99,97\%) e etanol (J. T. Backer 99,9\%).

Os experimentos realizados em um potenciostato/galvanostato Auto-Lab PGSTAT 302N. Antes dos experimentos borbulhou-se gás argônio na solução durante 20 minutos para remoção do oxigênio dissolvido e durante o experimento manteve-se o fluxo constante na parte superior da célula.

O eletrodo de trabalho foi lixado em lixa 2000 e em seguida procedeu-se o polimento com pastas de diamante de diferentes granulometrias 9 mícron, 6 mícron e 3 mícron (Buehler) até obtenção de uma superfície espelhada. Isto tem por objetivo garantir a reprodutibilidade da superfície durante os experimentos. Em seguida, o mesmo foi imerso em banho de ultrassom por cinco minutos numa solução $25 \%$ de etanol (J. T. Backer $99,9 \%$ ) em volume e mais três minutos em água ultrapura para limpeza completa.

O contra-eletrodo permaneceu por, pelo menos, quinze minutos imerso em solução sulfonídrica composta por: 50\%de ácido nítrico (Qhemis 65\%) e $50 \%$ de ácido sulfúrico PA (J.T Backer) para remoção total das impurezas presentes. E enxaguado repetidas vezes em água ultra pura, sistema Milli-Q.

\subsection{Sistema eletroquímico convencional}

Utilizou-se uma célula eletroquímica de vidro, com entradas para eletrodos na parte superior. $O$ volume de solução empregado foi de $45 \mathrm{~mL}$ e os experimentos foram conduzidos a temperatura ambiente, $23^{\circ} \mathrm{C} \pm 1^{\circ} \mathrm{C}$. 
O fator de rugosidade obtido foi de 2,2. Para o caso do paládio a adsorção e absorção de hidrogênio ocorrem no mesmo potencial, sendo assim, impossível diferenciar entre o $\mathrm{H}_{\text {upd }}$ e o $\mathrm{H}_{\text {ads }}$ (59) (60). Deste modo, o cálculo da área ativa não envolve determinação de carga de $H_{\text {upd }}$ e o método mais utilizado para determinação da área envolve medidas de formação e redução de $\mathrm{PdO}$, com a aproximação de $424 \mu \mathrm{Ccm}^{-2}$. Este valor está associado com a redução de uma monocamada do óxido na varredura negativa da voltametria cíclica. (61) (62) (63). Como contra-eletrodo optou-se por um eletrodo de platina platinizado. Escolhido devido sua grande área superficial e afastado do eletrodo de trabalho. Os potenciais foram medidos em relação ao eletrodo reversível de hidrogênio preparado com a mesma solução do eletrólito de suporte utilizado no experimento e localizado próximo ao eletrodo de trabalho.

\subsection{Transientes circuito aberto da seção 5.2.1}

Utilizou-se o hidróxido de potássio $1 \mathrm{molL}^{-1}$ (Sigma Aldrich, metal grade, 99,99\%) e metanol (J. T. Backer 99,97\%) em diversas concentrações: 0,05 $\mathrm{molL}^{-1}, 0,25 \mathrm{molL}^{-1}$ e $0,50 \mathrm{molL}^{-1}$.

Escolheu-se uma concentração do álcool por conjunto de experimento. No qual consistia em variar o tempo de polarização. Sendo eles: 100, 500 e 700 segundos em potencial de $1,1 \mathrm{~V}$ vs ERH. As medidas foram feitas em duplicatas em dias distintos para cada sistema.

\subsection{Transientes de circuito aberto e varredura rápida}

Devido ao fato de o paládio absorver uma grande quantidade de hidrogênio e isto alterar de forma significativa a superfície do eletrodo optou-se por fazer experimentos sequenciais com um mesmo pré tratamento para garantir repetibilidade e reprodutibilidade.

Escolheu-se um eletrólito de suporte e uma molécula orgânica para cada sequência de experimentos.

Seguiu-se a seguinte ordem:

1. Cem voltametrias com o eletrólito de suporte entre $0,350 \mathrm{~V}$ e 1,20 V; 
2. Cinquenta voltametrias com o composto orgânico entre $0,350 \mathrm{~V}$ $1,2 \mathrm{~V}$;

3. Transiente de circuito aberto sem rotação;

4. Transiente de circuito aberto sem rotação;

5. Transiente de circuito aberto sem rotação sem abertura de potencial;

6. Varredura rápida a $5 \mathrm{Vs}^{-1}$;

7. Transiente de circuito aberto a $1000 \mathrm{rpm}$;

8. Transiente de circuito aberto a $1000 \mathrm{rpm}$;

9. Transiente de circuito aberto a $2000 \mathrm{rpm}$;

10. Transiente de circuito aberto a $2000 \mathrm{rpm}$.

Realizou-se em duplicada para cada conjunto de eletrólito e composto orgânico. As medidas de transiente de circuito aberto foram feitas do seguinte modo: 20 segundos em $0,05 \mathrm{~V}, 500$ segundos em $0,90 \mathrm{~V}$ e abertura do potencial.

No caso da varredura rápida, após o tempo de polarização fez-se uma varredura rápida linear de $5 \mathrm{Vs}^{-1}$ para determinar a quantidade de óxido formado. E nos que apresentam rotação, a mesma iniciou-se poucos segundos antes de o potencial ser aberto.

Os experimentos para a determinação da quantidade de óxidos na solução sem o composto orgânico foram realizados em dias diferentes e com um procedimento adaptado que consistia na realização de cem voltametrias, polarização por 500 segundos e varredura linear catódica com velocidade de $0,1 \mathrm{Vs}^{-1}$. Dois dias diferentes e duas vezes em cada um. 


\section{Resultados e discussão}

Os resultados foram divididos em três seções. Na primeira, 5.1, são apresentados os resultados da influência do cátion metálico na eletro-oxidação do metanol e etanol utilizando a técnica de voltametria cíclica. Na seguinte, 5.2, são discutidos os transientes de circuito aberto em metanol e etanol em modo estacionário. Finalmente, a seção 5.3 é feita a análise do efeito da rotação nos dois sistemas.

\subsection{Influência de cátions alcalinos na eletro-oxidação de metanol e etanol em meio alcalino}

A Figura 8 mostra os voltamogramas cíclicos do eletrodo de paládio a $0,1 \mathrm{Vs}^{-1} \mathrm{em} 1 \mathrm{molL}^{-1}$ de $\mathrm{MOH}$ (com $\mathrm{M}=\mathrm{Li}$ ou $\mathrm{K}$ ). São observadas pequenas diferenças na região de formação de óxidos acima de 0,75 V. Indicando que existe uma quantidade ligeiramente maior formada quando se utiliza 0 hidróxido de potássio. Na varredura reversa é possível observar uma diferença mais acentuada no pico de redução de óxido, no qual fica claro um valor menor de corrente para o sistema com lítio. Isso mostra que existe realmente menor quantidade de óxido a ser reduzida,

Figura 7: Voltamograma cíclico em paládio policristalino a $100 \mathrm{mVs}^{-1} \mathrm{em}$ dois eletrólitos diferentes: hidróxido de lítio (linha vermelha) e hidróxido de potássio (linha preta).

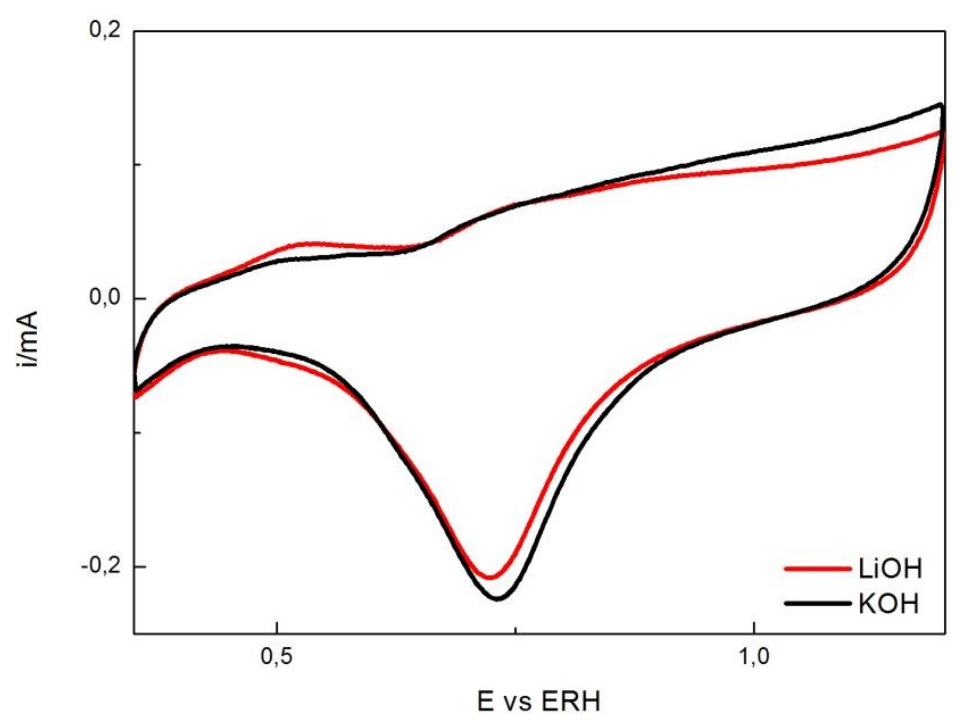


Na Figura 8 (a) são mostrados os voltamogramas cíclicos na presença de metanol em hidróxido de lítio e hidróxido de potássio ambos a $1 \mathrm{molL}^{-1}$. É possível visualizar que no hidróxido de lítio o pico de ativação está centrado em $0,81 \mathrm{~V}$ para o outro o valor é de $0,74 \mathrm{~V}$, ou seja, existe uma diferença de $0,07 \mathrm{~V}$. Isto indica que existe uma diferença pequena na quantidade de óxido formado. Já o pico na varredura reversa os picos estão deslocados para potenciais menores $0,68 \mathrm{~V}$ para o cátion menor e 0,62 para o outro.

Na Figura 8 (b) são apresentados os voltamogramas cíclicos da eletrooxidação de etanol nos mesmos eletrólitos da Figura 8 (a). O pico de ativação para o hidróxido de potássio é no valor de $0,72 \mathrm{~V}$ e para outro é de $0,73 \mathrm{~V}$. Por ser uma diferença muito pequena não é possivel afirmar que há diferenças entre os tipos óxidos formados. O pico de reativação possui valor de corrente maior que o de ativação para o caso do cátion menor e no caso do outro cation os valores são similares.

A eletro-oxidação de metanol apresenta valores de corrente máxima em torno de 0,90 mA. Enquanto que no caso do etanol valores superiores a 3,50 mA são observados. Quando se utilizou hidróxido de potássio observou-se que ambos os picos de ativação estão bem próximos com diferença mínima de 0,01 V. Já no caso do hidróxido de lítio a diferença é mais acentuada de 0,08 V. 
Figura 8: Voltamogramas ciclicos a $100 \mathrm{mVs}^{-1}$ em Pd policristalino em dois eletrólitos diferentes $1 \mathrm{molL}^{-1}$ (a) $0,250 \mathrm{molL}^{-1}$ de metanol e (b) $0,250 \mathrm{molL}^{-1}$ de etanol.
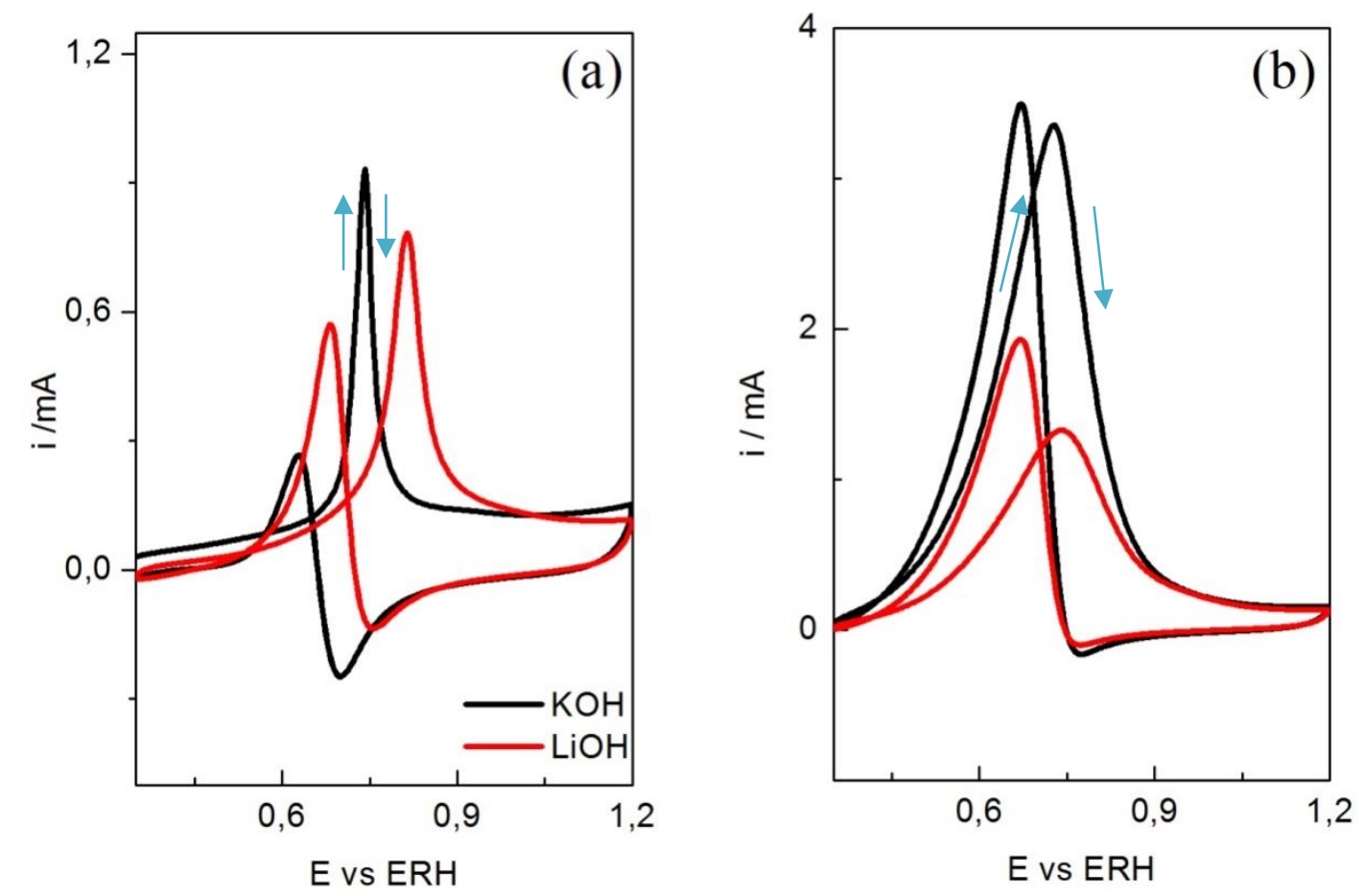

\subsection{Transientes de circuito aberto em modo estacionário}

\subsubsection{Escolha das condições experimentais}

Num primeiro momento a escolha do potencial aplicado foi feita tendo como base dados da literatura (64). Em 1,1 V já é possível obter uma camada completa de óxido de paládio. Assim, foram feitos experimentos em três tempos de polarização diferentes para verificar qual o efeito disto nos transientes de circuito aberto em paládio. Na Figura 9 são mostrados os transientes em $0,50 \mathrm{molL}^{-1}$ de metanol com três tempos de polarização: 100 , 500 e 700 segundos. Observa-se que existe um aumento do tempo necessário para se chegar ao equilíbrio com o aumento do tempo de polarização. Isto indica que a quantidade de óxido formada depende diretamente do tempo de polarização e o potencial final não dependeu deste fator. Mesmo fenômeno observado para o sistema de platina e metanol (30). 
Figura 9: Transientes de circuito aberto em diferentes tempos de polarização em $0,50 \mathrm{molL}^{-1}$ de metanol e $1 \mathrm{molL}^{-1}$ de hidróxido de potássio

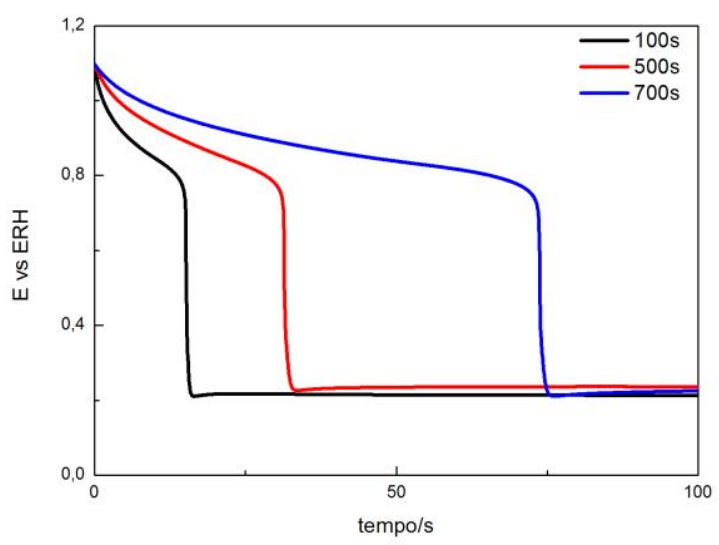

Na Figura 10 (a) o tempo de polarização é de 100 segundos. O tempo de decaimento para a menor concentração é de 80 segundos, bem maior que para a segunda foi de 18 segundos e um pouco diferente do que para 0,50 $\mathrm{molL}^{-1}$ que ficou em 15 segundos. O mesmo fenômeno foi observado por Sitta e Varela (30) em $0,50 \mathrm{~mol} \mathrm{~L}^{-1}$ metanol em platina. Os tempos foram de aproximadamente 25 segundos de decaimento para 100 segundos de polarização.

A mesma tendência foi observada na Figura 10 (b), com tempo de polarização de 700 segundos, um tempo alto de decaimento foi visto para a concentração de $0,05 \mathrm{molL}^{-1} \mathrm{com}$ cerca de 480 segundos, uma diminuição grande foi observada na segunda concentração e uma pequena para a maior concentração. A concentração não interferiu nos valores finais de potencial.

Se consideramos que em um mesmo tempo de polarização a quantidade de óxido formada é a mesma (32) (33), as diferenças de velocidade observadas no consumo de óxido na superfície de paládio oxidada dependem diretamente da concentração do metanol presente no eletrólito. Deste modo, observa-se que o tempo de decaimento aumenta com a diminuição da concentração de metanol. O que foi confirmado pela Figura 10 (a) e (b). 
Figura 10: Transientes de circuito aberto em diferentes concentrações de 1 $\mathrm{mol} \mathrm{L}^{-1}$ de $\mathrm{KOH}$ sobre paládio. (a) 100 segundos e (b) 700 segundos.
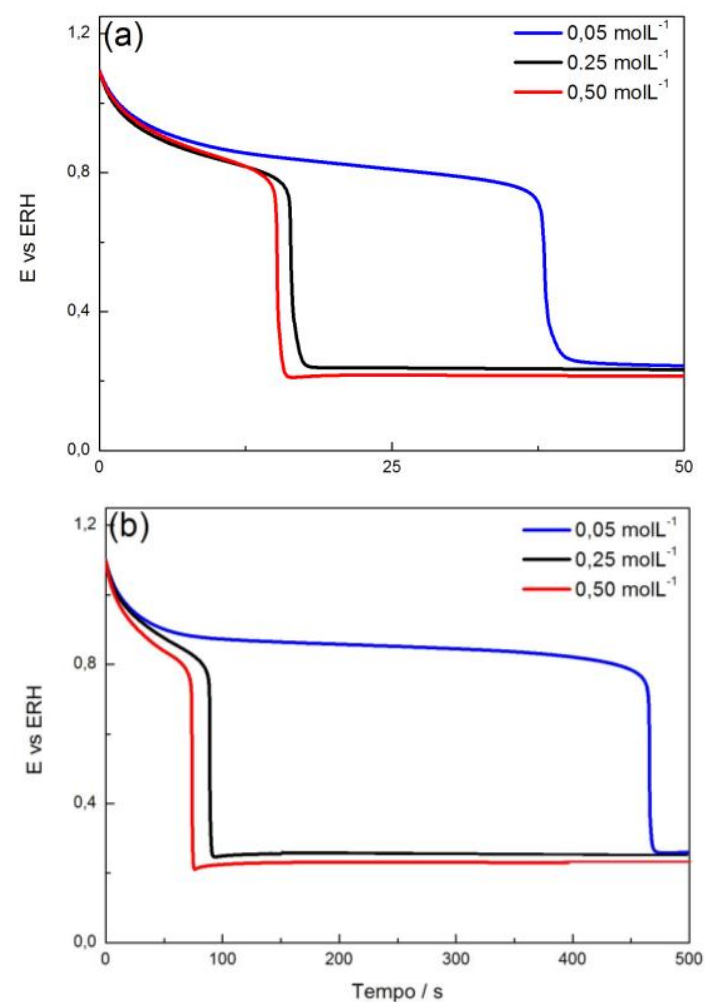

Com base no que foi discutido nesta seção optou-se por realizar experimentos com $0,250 \mathrm{molL}^{-1}$ de metanol e $1 \mathrm{molL}^{-1}$ de hidróxido de potássio e polarizar por 500 segundos. A curva pode ser vista na Figura 11 (b). Porém, quando o mesmo procedimento foi utilizado para o hidróxido de lítio obteve-se uma curva diferente, Figura 11 (a). O potencial decai para o valor de 0,80 V e se torna estacionário neste ponto. Indicando um comportamento diferente do que ocorre com o sistema com hidróxido de potássio. 
Figura 11: Transientes de circuito aberto $0,250 \mathrm{molL}^{-1}$ de metanol (a) $1 \mathrm{molL}^{-1}$ de $\mathrm{LiOH}$ e (b) $1 \mathrm{molL}^{-1}$ de $\mathrm{KOH}$ com tempo de polarização de 700 segundos.

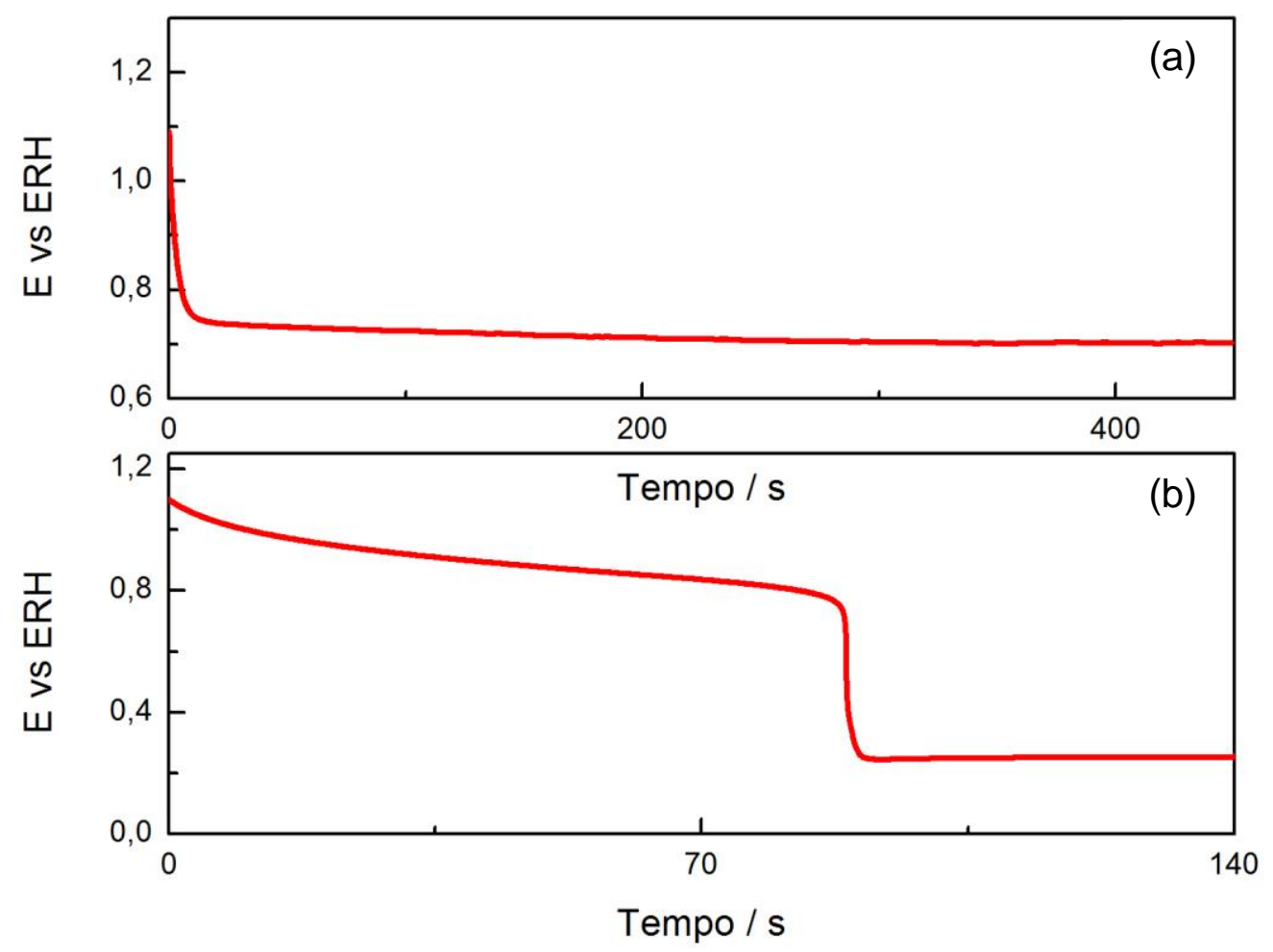

Fazendo uma análise mais precisa deste experimento é possível dividir a curva obtida em quatro partes, como detalhado na Figura 12. Na região 1 localizada logo após a abertura do potencial espera-se que exista uma mistura de compostos de Pd (IV) e Pd (II). Quando se chega ao potencial entre 0,90 V e 0,80 V representada na região 2 temos a redução do Pd (IV) e formação da camada óxido de paládio é favorecida e este é consumido por meio da reação direta do metanol por meio do mecanismo de Eley - Rideal. Na região 3 as reações ocorrem por mecanismo denominado "reações conjugadas" no qual o metanol reage até seus produtos finais diminuindo potencial para valores próximos a 0,30 V. E na região 4 superfície está em equilíbrio com solução. 
Figura 12: Esquema representativo das etapas reacionais

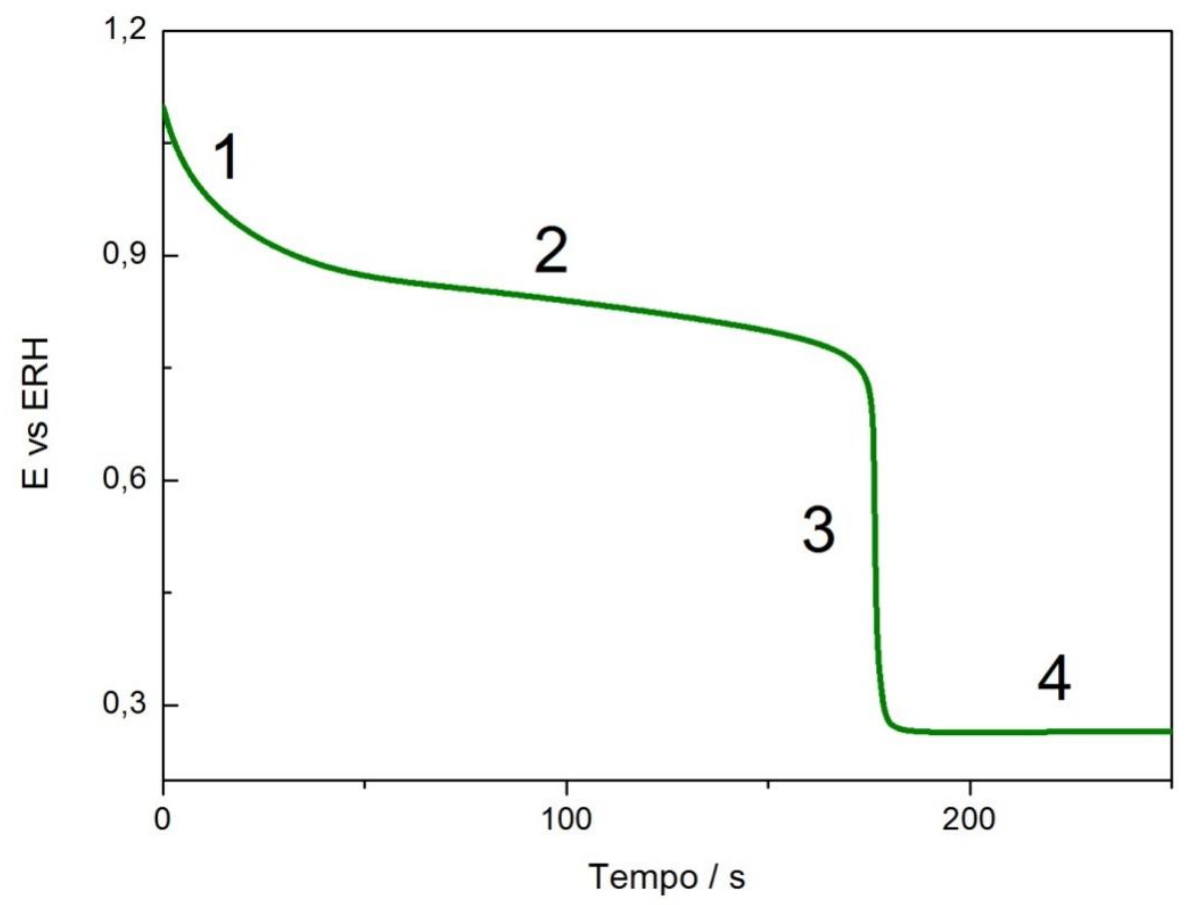

No sistema com hidróxido de lítio pode-se observar ocorre apenas a primeira etapa de redução dos compostos de paládio e parte da fase 2. O óxido chega a ser formado, mas o cátion lítio provavelmente adsorve sobre o mesmo bloqueando a aproximação do metanol e consequentemente a reação não acontece.

Como a ideia do presente trabalho era comparar transientes de circuito aberto em dois eletrólitos e com dois orgânicos diferentes optou-se por reduzir o potencial aplicado de 1,1 V na Figura 11(a) para 0,9 V. Desse modo, foi possível obter curvas com os mesmo fenômenos envolvidos para comparação.

\subsection{2 Óxidos e transientes estacionários}

As quantidades de óxido formado foram determinados pela área de redução de óoxidos e podem ser observadas na Tabela 1. O método utilizado para o cálculo da quantidade de óxido real em cada experimento foi o mesma utilizado para o cálculo da área ativa do eletrodo e está escrita em detalhes na 
seção materiais e métodos. Em seguida, dividiu-se o valor obtido pela area real do eletrodo. Obtendo, deste modo, o número de monocamadas de óxido.

Quando se observa apenas a quatidade de óxido formada na ausência de compostos orgânicos, temos que o valor no sistema com lítio chega a ser aproximadamente a metade do visto no caso do potássio. Indicando que o menor cátion bloqueia a superfície mais eficientemente. Este fenômeno está associado com uma alta densidade de carga no primeiro que se adsorve mais eficientemente.

Tabela 1: Quantidade de óxido em diferentes sistemas em quantidade de óxido (ML)

\begin{tabular}{|cc|}
\hline Eletrólito & Quantidade de Óxido (ML) \\
\hline $\mathrm{LiOH}\left(1 \mathrm{molL}^{-1}\right)$ & 0,60 \\
\hline $\mathrm{KOH}\left(1 \mathrm{molL}^{-1}\right)$ & 1.18 \\
\hline $\mathrm{LiOH}\left(1 \mathrm{molL}^{-1}\right)+\mathrm{CH}_{3} \mathrm{OH}\left(0,250 \mathrm{molL}^{-1}\right)$ & 0,60 \\
\hline $\mathrm{KOH}\left(1 \mathrm{molL}^{-1}\right)+\mathrm{CH}_{3} \mathrm{OH}\left(0,250 \mathrm{molL}^{-1}\right)$ & 0,90 \\
\hline $\mathrm{LiOH}\left(1 \mathrm{molL}^{-1}\right)+\mathrm{CH}_{3} \mathrm{CH}_{2} \mathrm{OH}\left(0,250 \mathrm{molL}^{-}\right.$ & 0,46 \\
\hline $\mathrm{KOH}\left(1 \mathrm{molL}^{-1}\right)+\mathrm{CH}_{3} \mathrm{CH}_{2} \mathrm{OH}\left(0,250 \mathrm{molL}^{-}\right.$ & \\
$1)$ & 0,53 \\
\hline
\end{tabular}

Considerando apenas os sistemas que possuem hidróxido de lítio como eletrólito é possível vizualizar que os valores diminuem com o tamanho da molécula orgânica envolvida, ou seja, é maior sem a presença de nenhum, diminui um pouco com a presença de metanol e diminui ainda mais com a presença do etanol.

Utilizando análise similar para sistemas que apresentam o hidróxido de potássio é possível observar o mesmo fenômeno. Uma maior quantidade de óxido formado na ausência de compostos orgânicos, a diminuição na presença do metanol e outra diminuição na presença do etanol. A principal diferença entre os dois sistemas está na magnitude do decaimento. Ela ocorre de maneira muito mais acentuada no sistema com maior cátion. Isto pode ser justificado pelo fato da maior mobilidade destes íons na dupla camada elétrica o que facilita a entrada do metanol e etanol nesta região. Na Figura 13 (a) é mostrada a curva obtida no procedimento de circuito aberto para a interação com o metanol. Pode-se observar que o tempo necessário para o consumo de 
óxido é maior para o sistema com hidróxido de potássio. Isto está vinculado diretamente com a quantidade maior de óxido que é gerada durante o processo polarização como discutido anteriormente. Como as diferenças nos valores entre os dois eletrólitos são acentuadas, o tempo difere substancialmente. E no final convergem a um mesmo potencial.

Figura 13: Transientes de circuito aberto em $1 \mathrm{molL}^{-1}$ de $\mathrm{LiOH}$ ou $\mathrm{KOH}$ (a) $0,250 \mathrm{molL}^{-1}$ de metanol e (b) $0,250 \mathrm{molL}^{-1}$ etanol. Tempo de polarização de 500 s.
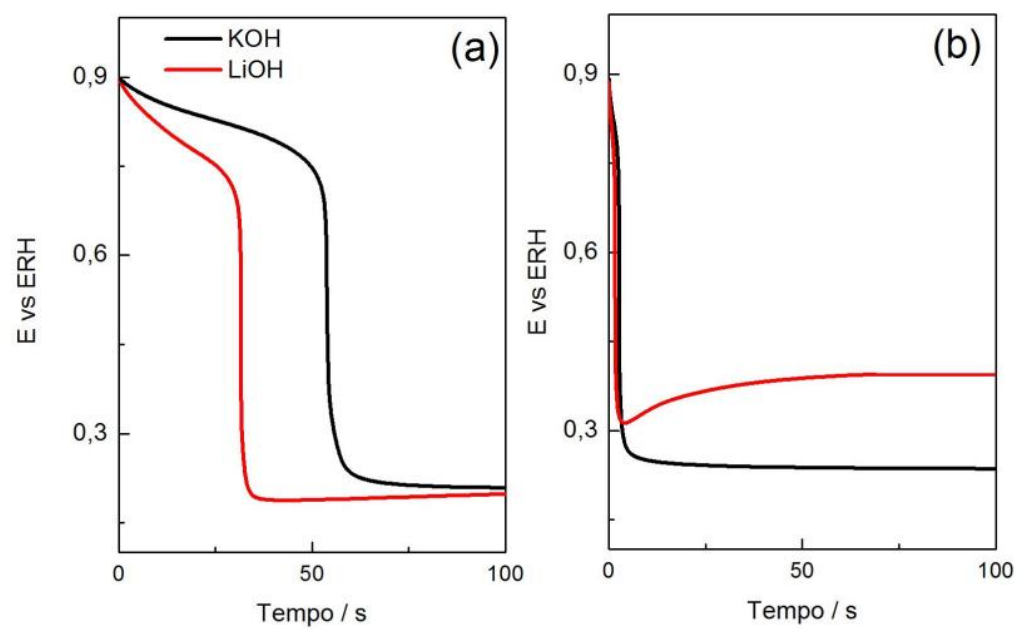

Na Figura 13 (b) é mostrada a curva de transiente de circuito aberto para o caso do etanol. Pode-se observar que as curvas não diferem muito em termos temporais. Facilmente entendido pelo fato das quantidades de óxidos serem próximas. No transcorrer do tempo os valores não convergem como no caso anterior, sendo que para o caso do hidróxido de lítio o potencial é de $0,39 \mathrm{~V}$ e para o caso do hidróxido de potássio o valor é de $0,23 \mathrm{~V}$, e o potencial se mantém estacionário por tempos longos.

A curva em vermelho, na mesma figura, desce até um potencial mínimo, depois aumenta e com o tempo se torna estacionária. Na primeira fase temos 0 consumo total de óxido de paládio, num segundo momento existe uma provável adsorção do cátion e na terceira fase a interface entra em equilibrio e o potencial permanece constante. Isto muito provavelmente tem relação com a alta densidade de carga deste íon. Maiores detalhes serão descritos na seção 5.3.1. 
Os tempos necessários para os sistemas entrarem em equilíbrio são ligeiramente diferentes para os dois orgânicos. O etanol necessita de um tempo muito menor que o metanol o que é justificado pela quantidade de óxido.

\subsection{Transientes de circuito aberto em rotação}

\subsubsection{Metanol}

Na Figura 14 são mostrados os transientes de circuito aberto de metanol sob efeito de diferentes velocidades de rotação e com dois eletrólitos diferentes. Em (a) foi utilizado hidróxido de lítio e em (b) hidróxido de potássio. Pode-se observar que a rotação altera o tempo necessário de decaimento. Isto indica que existem, pelo menos, duas fases na eletro-oxidação de metanol em paládio, e que a rotação favorece uma delas.

Tendo em vista os transientes é possível propor um mecanismo da interação entre as espécies orgânicas e a superfície oxidada. A formação do óxido de paládio foi descrita na seção 2.3 , e as equações serão repetidas aqui para fins didáticos,

$$
\begin{gathered}
\mathrm{Pd}+\mathrm{OH}^{-} \leftrightarrow \mathrm{Pd}-\mathrm{OH}_{\mathrm{ads}}+\mathrm{e}^{-} \\
\mathrm{Pd}-\mathrm{OH}_{\mathrm{ads}}+\mathrm{OH}^{-} \leftrightarrow \mathrm{Pd}-\mathrm{O}+\mathrm{H}_{2} \mathrm{O}+\mathrm{e}^{-} \\
\mathrm{Pd}-\mathrm{OH}_{\mathrm{ads}}+\mathrm{Pd}-\mathrm{OH}_{\mathrm{ads}} \leftrightarrow \mathrm{Pd}-\mathrm{O}+\mathrm{H}_{2} \mathrm{O}[4]
\end{gathered}
$$

O metanol presente no sistema consume primeiramente a camada mais externa de óxido por meio de um mecanismo Eley-Redeal. E para isso ocorrer o recobrimento deve ser alto e as equações [6],[7] e [8] ocorrem por esse mecanismo. (30) (32). 
Figura 14: Transientes de circuito aberto de $0,250 \mathrm{molL}^{-1}$ de metanol em paládio policristalino em diferentes velocidades (a) $\mathrm{LiOH} 1 \mathrm{molL}^{-1}$ (b) $\mathrm{KOH} 1$ $\mathrm{molL}^{-1}$
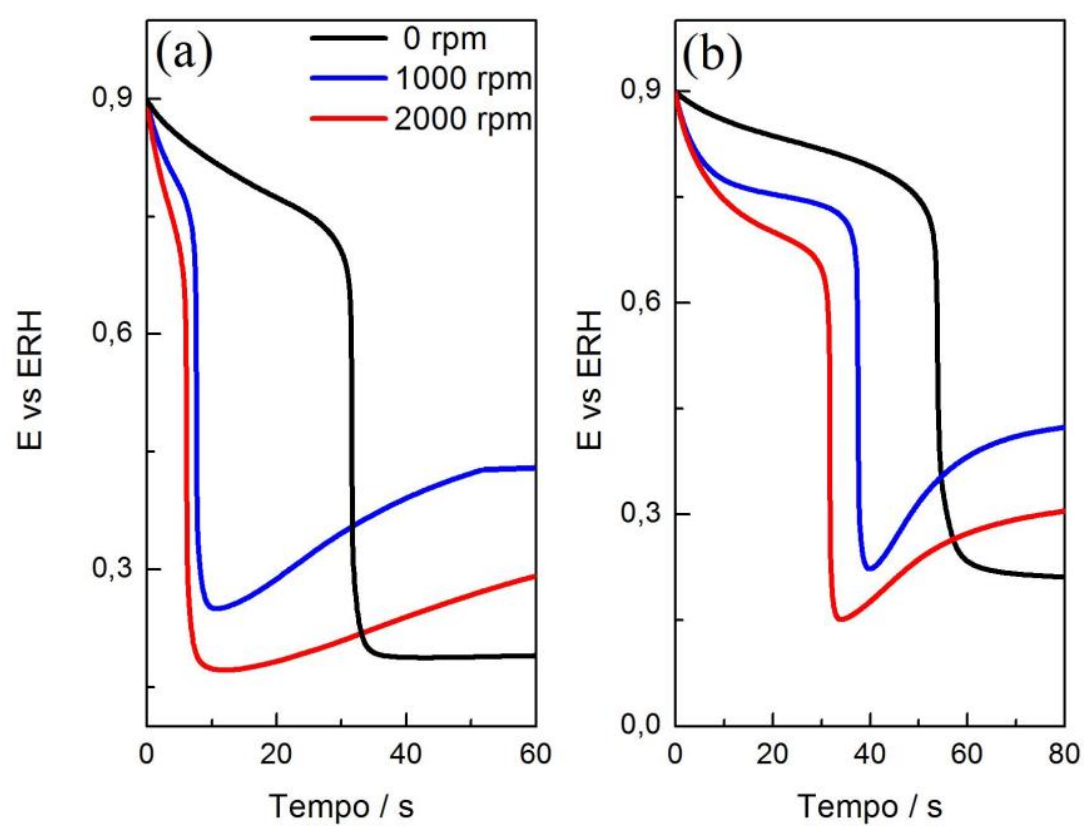

$$
\mathrm{PdO}+\mathrm{H}_{3} \mathrm{COH} \rightarrow \mathrm{Pd}+\mathrm{H}_{2} \mathrm{CO}+\mathrm{H}_{2} \mathrm{O}
$$

Os aldeídos não são estáveis em meio alcalino e reagem com outras espécies em solução. A etapa descrita na equação [6] libera sítios ativos e favorece a reação [7].

$$
2 \mathrm{PdO}+\mathrm{H}_{3} \mathrm{COH} \rightarrow 2 \mathrm{Pd}+\mathrm{HCOOH}+\mathrm{H}_{2} \mathrm{O} \text { [7] }
$$

A reação entre dois sítios de paládio e metanol produz ácido fórmico que não é estável em meio alcalino e é rapidamente convertido ao ânion formiato. Este é considerado produto final quando a reação [8] não ocorre. Para ela acontecer, é preciso haver três sítios próximos.

$$
3 \mathrm{PdO}+\mathrm{H}_{3} \mathrm{COH} \rightarrow 3 \mathrm{Pd}+\mathrm{CO}_{2}+2 \mathrm{H}_{2} \mathrm{O}
$$


Como já foram comentadas as reações descritas em [6], [7] e [8] necessitam de uma alta cobertura de óxidos. Podlovchenko et al. (34) sugerem uma cobertura superficial entre 0,8 e 1 monocamada para estas reações.

Em seguida, há uma queda muito rápida de potencial e a concentração de $\mathrm{CO}_{2}$ e $\mathrm{CO}$ aumentam no sistema (66). Essas reações são denominadas "reações conjugadas", são auto-catalíticas e ocorrem com a adsorção do álcool. São mostradas nas equações de [9]-[13].

$$
\begin{aligned}
& \mathrm{Pd}+\mathrm{H}_{3} \mathrm{COH} \rightarrow \mathrm{Pd}-\mathrm{H}_{2} \mathrm{COH}_{\mathrm{ad}}+\mathrm{H}^{+}+\mathrm{e}^{-} \text {[9] } \\
& \mathrm{Pd}+\mathrm{Pd}-\mathrm{H}_{2} \mathrm{COH}_{\mathrm{ad}} \rightarrow \mathrm{Pd}_{2}-\mathrm{HCOH}_{\mathrm{ad}}+\mathrm{H}^{+}+\mathrm{e}^{-} \text {[10] } \\
& \mathrm{Pd}+\mathrm{Pd}_{2}-\mathrm{HCOH}_{\mathrm{ad}} \rightarrow \mathrm{Pd}_{3}-\mathrm{COH}_{\mathrm{ad}}+\mathrm{H}^{+}+\mathrm{e}^{-} \text {[11] } \\
& \mathrm{Pd}_{3}-\mathrm{COH}_{\mathrm{ad}} \rightarrow \mathrm{Pd}-\mathrm{CO}_{\mathrm{ad}}+2 \mathrm{Pd}+\mathrm{H}^{+}+\mathrm{e}^{-} \text {[12] } \\
& \mathrm{Pd}_{3}-\mathrm{COH}_{\mathrm{ad}} \rightarrow \mathrm{Pd}_{2}-\mathrm{CO}_{\mathrm{ad}}+\mathrm{H}^{+}+\mathrm{Pd}+\mathrm{e}^{-}[13]
\end{aligned}
$$

O decréscimo rápido do potencial de circuito aberto e a rápida produção de $\mathrm{CO}_{2}$ pode ser explicado através de um mecanismo auto-catalítico. O termo é utilizado para identificar a situação na qual um reagente participa de um conjunto de reações que tem como resultado a produção de moléculas de sua própria espécie. De uma forma genérica, uma espécie $A$ reage com $B$ dando como resultado $2 \mathrm{~A}$. Considerando que $\mathrm{B}$ não limita a reação, o aumento da quantidade de $A$ desencadeia o seu aumento exponencial no sistema. No presente sistema A seria sítios de paládio livres e B o metanol. Neste caso, apesar de um aumento exponencial, a quantidade de sítios livres é limitada pela área total do eletrodo.

A formação de monóxido de carbono pode ocorrer de duas maneiras distintas. $O$ formado em [12] é denominado linear e ocupa apenas um sítio e o segundo é em ponte e ocupa dois sítios. Ambos foram comprovados por técnicas espectroscópicas (56).

O CO pode ser convertido a dióxido de carbono pela seguinte relação (67).

$$
\mathrm{Pd}_{\mathrm{x}}-\mathrm{CO}+\mathrm{PdO} \rightarrow(\mathrm{x}+1) \mathrm{Pd}+\mathrm{CO}_{2}
$$


As reações de [9] a [14] dependem de sítios livres para ocorrer e, portanto, concorrem com a adsorção de $\mathrm{OH}^{-}$proveniente do eletrólito. Do mesmo modo dos ânions em meio ácido (30). E os elétrons dessas reações são provenientes das reações acopladas no chamado "Chemical Short" ou "Internal Short Circuit". Nestas etapas considera-se o que o metanol é adsorvido pelo carbono.

Uma parte da eletro-oxidação do metanol ocorre por meio do mecanismo de Langmuir - Hinshelwod, ou seja, os resíduos da molécula de metanol reagem com uma espécie oxigenada adjacente, seja $\mathrm{Pd}-\mathrm{O}$ :

$$
2\left(\mathrm{Pd}-\mathrm{CH}_{2} \mathrm{OH}\right)_{\mathrm{ad}}+\mathrm{Pd}-\mathrm{O} \rightarrow 3 \mathrm{Pd}+2 \mathrm{H}_{2} \mathrm{CO}+\mathrm{H}_{2} \mathrm{O}
$$

Ou Pd-OH,

$$
\mathrm{Pd}-\mathrm{CH}_{2} \mathrm{OH}_{\mathrm{ad}}+\mathrm{Pd}-\mathrm{OH} \rightarrow 2 \mathrm{Pd}+\mathrm{H}_{2} \mathrm{CO} \mathrm{H}_{2} \mathrm{O} \text { [16] }
$$

Na Figura 15 é mostrado um gráfico de como a rotação interfere no transiente de circuito aberto nos dois eletrólitos: hidróxido de sódio e hidróxido de potássio. 
Figura 15: Variação temporal dos transientes de circuito aberto de metanol $0,250 \mathrm{molL}^{-1}$ em função da rotação em dois eletrólitos: hidróxido de lítio e hidróxido de potássio.

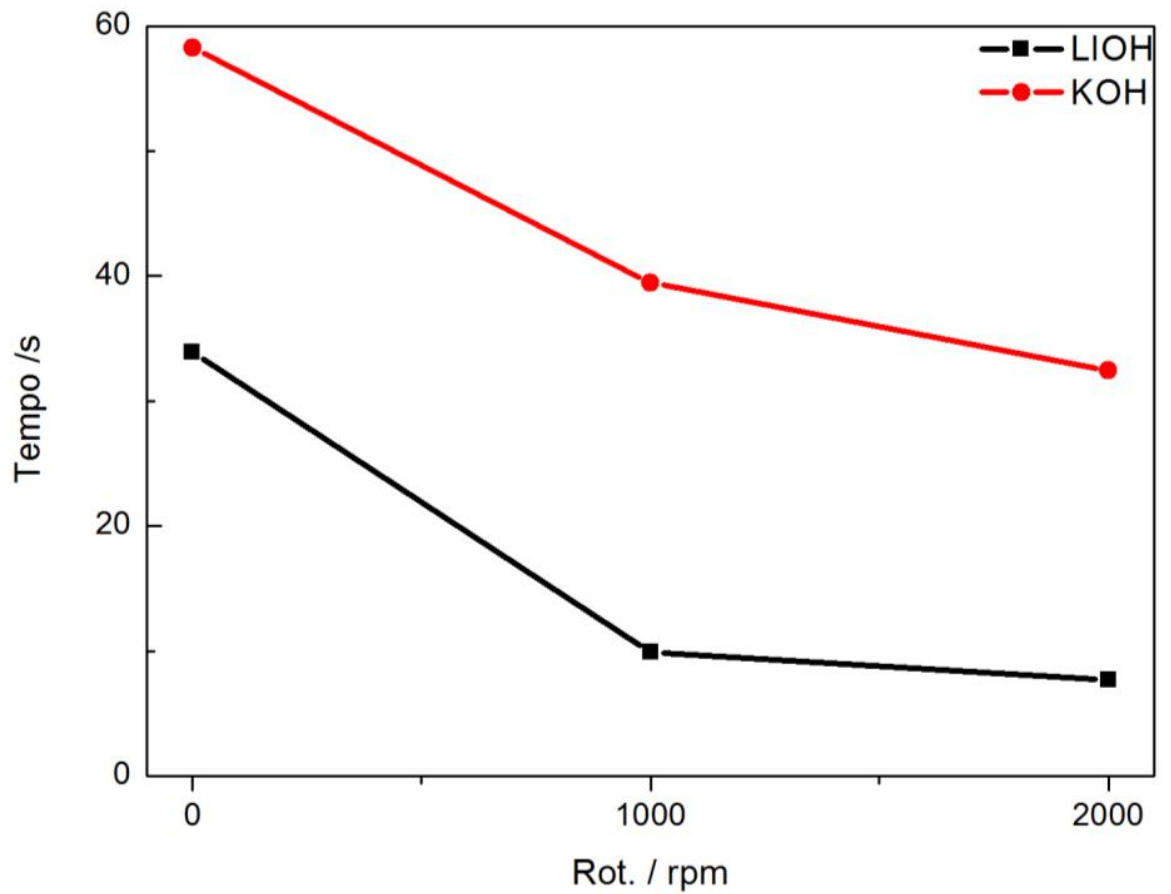

É possível observar que a queda temporal é acentuada em ambos os eletrólitos quando o valor da rotação vai de $0 \mathrm{rpm}$ a $1000 \mathrm{rpm}$. No entanto, praticamente não varia no intervalo de 1000 rpm a 2000 rpm.

A rotação do eletrodo promove um efeito de transporte de massa à superfície eletródica, facilitando a chegada de metanol na sua superfície e acelerando as reações que ocorrem diretamente entre o orgânico e o óxido, ou seja, as equações [6], [7] e [8]. Sendo esse o principal motivo na redução do tempo global nos transientes.

A rotação também interferiu no valor do potencial final de equilíbrio. Os valores podem ser vistos na Figura 16.

Os valores finais de potencial apresentam a mesma dependência com a rotação nos dois eletrólitos. Sendo o menor valor no sistema estacionário, o maior em 1000 rpm e em seguida o valor decai em 2000 rpm.

A estabilidade do $\mathrm{Pd}-\mathrm{OH}$ e do $\mathrm{Pd}-\mathrm{O}$ que dependem diretamente do cátion do eletrólito de suporte. Esta dependência influencia tanto a força de adsorção do $\mathrm{OH}^{-}$em etapas que concorre com a adsorção do metanol quanto em sua 
reatividade nas etapas que ocorre o "chemical short" ou "internal short circuit" e na oxidação via Langmuir - Hinshelwood. Como foi visto na Figura 13 (a).

Figura 16: Rotação em função do potencial para dois eletrólitos: hidróxido de lítio e hidróxido de potássio.

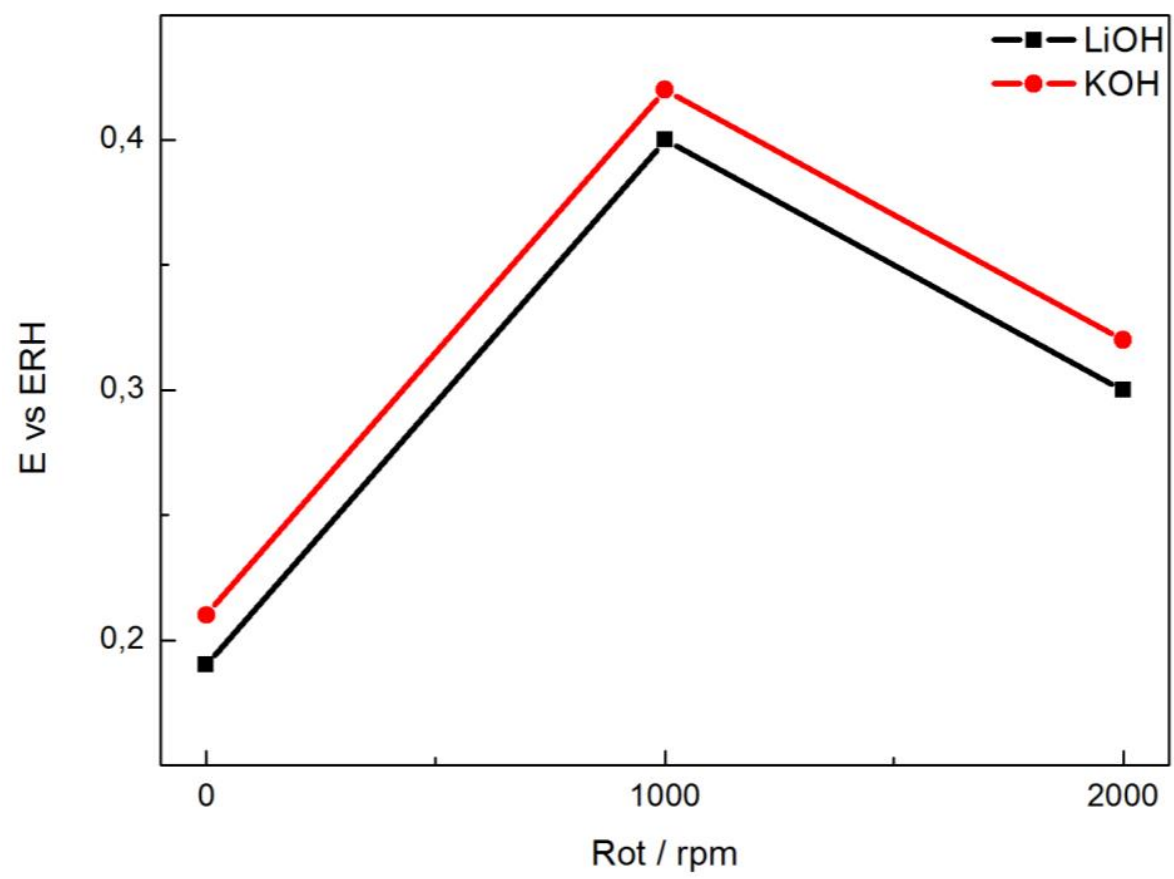

Não é possível afirmar se existe uma tendência de redução com 0 aumento da rotação ou se não há nenhum padrão e o potencial varia de forma aleatória.

Mas é possível afirmar que se o primeiro comportamento for o correto, isto está relacionado com o equilíbrio dinâmico da dupla camada em conjunto com o transporte de massa da solução. Em rotações com valores muito altos o equilíbrio é tão rápido que seria equivalente ao sistema em regime estacionário. 


\subsubsection{Etanol}

Na Figura 17 são mostrados os transientes de circuito aberto para o etanol em dois eletrólitos diferentes: (a) hidróxido de lítio e (b) hidróxido de potássio.

Ao contrário do que foi visto para o caso do metanol, a rotação não altera o tempo de decaimento ao potencial de equilíbrio. Indicando que as rotas reacionais possíveis independem da perturbação do sistema.

Figura 17: Transientes de circuito aberto de $0,250 \mathrm{molL}^{-1}$ etanol em paládio policristalino em diferentes velocidades de rotação (a) LiOH $1 \mathrm{molL}^{-1}$ (b) $\mathrm{KOH} 1 \mathrm{molL}^{-1}$
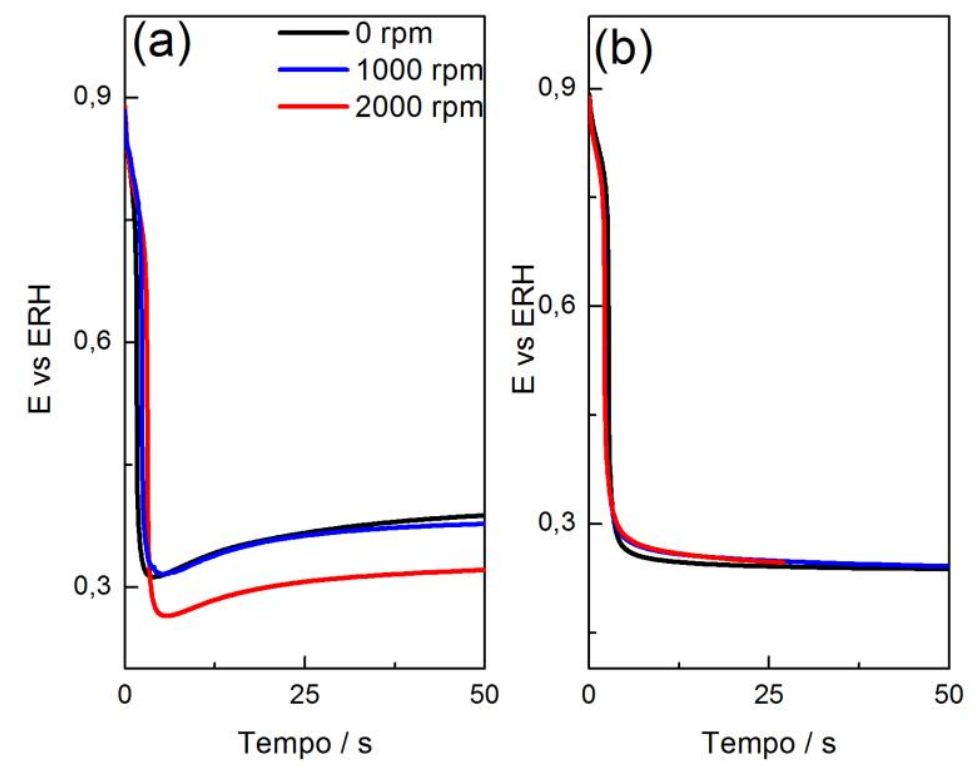

Comparando os transientes de circuito aberto entre o metanol e o etanol pode-se observar que o tempo requerido para o consumo de óxidos é maior para a primeira molécula. $O$ cálculo da quantidade de óxidos na presença de etanol indica uma menor quantidade daquela formada na presença de metanol. Tal fenômeno pode estar conectado a maior habilidade do etanol em reagir com superfície oxidadas. Este álcool utiliza-se de rotas que necessitam de mais sítios livres, ou via mecanismo de Eley-Riedel. Por outro lado a reação de eletro-oxidação completa do etanol é mais complicada que a do metanol devido, em grande parte, a sua menor adsorção na superfície e dificuldades na 
quebra da ligação C-C. Assim, para que haja formação de $\mathrm{CO}_{2}$ necessita-se de um número maior de sítios livres.

A seguir é proposto um mecanismo para a interação do etanol com os óxidos de paládio, tendo como base os dados mecanísticos extraídos de cálculos teóricos (58) e espectrometria de infravermelho (57). De forma análoga ao metanol, na primeira etapa do transiente, em condições de elevado recobrimento superficial de óxidos, a oxidação pode ocorrer via mecanismo de Eley-Riedel gerando aceltadeído [17] e ácido acético [18] .

$$
\begin{gathered}
\mathrm{CH}_{3} \mathrm{CH}_{2} \mathrm{OH}+\mathrm{Pd}-\mathrm{O} \rightarrow \mathrm{Pd}+\mathrm{CH}_{3} \mathrm{CHO}+\mathrm{H}_{2} \mathrm{O}[17] \\
\mathrm{CH}_{3} \mathrm{CH}_{2} \mathrm{OH}+2 \mathrm{Pd}-\mathrm{O} \rightarrow 2 \mathrm{Pd}+\mathrm{CH}_{3} \mathrm{COOH}+\mathrm{H}_{2} \mathrm{O} \text { [18] }
\end{gathered}
$$

Após essa primeira etapa, a disponibilidade de sítios livres permite a adsorção do etanol, tanto pelo oxigênio quanto pelo carbono, e sua consequente de-hidrogenação, como mostrado na Figura 6, até a obtenção da espécie $\mathrm{CH}_{3} \mathrm{CO}_{\text {ad. }}$. Quando esta espécie (acetaldeído adsorvido) não dessorve para a solução a reação em superfície pode ocorrer por dois caminhos: (1) adsorção e de-hidrogenação do grupo $\mathrm{CH}_{3}$ (etapas de 19-21) seguido da ruptura da ligação C-C; (2) quebra da ligação $\mathrm{C}-\mathrm{C}$ (etapa 22) gerando $\mathrm{CH} 3 \mathrm{e}$ $\mathrm{CO}$ adsorvidos. A reações envolvidas são descritas a seguir:

(1) Desidrogenação seguido da ruptura da ligação C-C

$$
\begin{aligned}
& \mathrm{Pd}-\mathrm{CH}_{3} \mathrm{CO}_{\mathrm{ad}}+\mathrm{Pd} \rightarrow \mathrm{Pd}_{2}-\mathrm{CH}_{2} \mathrm{CO}_{\mathrm{ad}}+\mathrm{H}^{+}+\mathrm{e}^{-}[19] \\
& \mathrm{Pd}_{2}-\mathrm{CH}_{2} \mathrm{CO}_{\mathrm{ad}}+\mathrm{Pd} \rightarrow \mathrm{Pd}_{3}-\mathrm{CHCO}_{\mathrm{ad}}+\mathrm{H}^{+}+\mathrm{e}^{-}[20] \\
& \mathrm{Pd}_{3}-\mathrm{CHCO}_{\mathrm{ad}}+\mathrm{xPd} \rightarrow \mathrm{Pd}_{2}-\mathrm{CH}+\mathrm{Pd}_{\mathrm{x}+1}-\mathrm{CO}
\end{aligned}
$$

Obs. Note que as moléculas C2 estão adsorvidas pelo carbono do grupo carbonila.

(2)Ruptura da ligação C-C: 


$$
\mathrm{Pd}-\mathrm{CH}_{3} \mathrm{CO}+\mathrm{xPd} \rightarrow \mathrm{Pd}-\mathrm{CH}_{3}+\mathrm{Pd}_{\mathrm{x}}-\mathrm{CO}
$$

Em ambos os casos há necessidade de sítios livres de $\mathrm{Pd}$ e o produto final é uma hidrocarboneto adsorvido e uma molécula de $\mathrm{CO}$, que pode estar adsorvida na configuração linear $(x=0)$ ou multicoordenado $(x>0)$

A oxidação de CO dá-se como descrita pelas equação 14, consumindo espécies oxigenadas e gerando sítios livres. A oxidação dos grupo $\mathrm{CH}_{\mathrm{x}}$ necessita de espécies oxigenadas, que podem vir do $\mathrm{PdOH}$ ou $\mathrm{PdO}$, gerando como produtos formaldeído, ácido fórmico ou $\mathrm{CO}$, neste caso é esperado uma dinâmica similar a do metanol.

Na prática é observado que menos de $3 \%$ do etanol é convertido a $\mathrm{CO}$ em meio ácido (29) devido à dificuldades na quebra da ligação $C-C$, sendo assim, a dinâmica de redução dos óxidos por etanol deve envolver, preferencialmente, as etapas de produção de acetaldeído ou ácido acético.

A produção auto-catalítica de sítios livres de paládio parece ser responsável pela reativação observada durante a varredura negativa nos voltamogramas cíclicos das espécies mostradas na Figura 7 e Figura 8. Durante o ciclo negativo a redução de óxidos é inicialmente dirigida pelo potencial e posteriormente, quando um valor mínimo de óxido é atingido a autocatálise se inicia. 


\section{Conclusões}

Os resultados experimentais das interações em circuito aberto entre os álcoois (metanol ou etanol) e a superfície de paládio mostraram comportamentos díspares. A quantidade de óxido formada variou bastante e depende tanto do álcool utilizado quanto do cátion. O sistema que apresentou a maior quantidade formada foi o de metanol com eletrólito de hidróxido de potássio. E a menor foi em etanol em hidróxido de lítio. A dependência com o cátion pode ser atribuída ao fato de cátions menores adsorverem diretamente no ânion que está ligado a superfície. Já os maiores apresentam uma camada de solvatação (água) entre o cátion e o ânion.

Por sua vez, a rotação interferiu de maneira distinta entre os dois álcoois estudados neste trabalho. Para o caso do metanol houve uma dependência entre a rotação e o tempo necessário para o sistema entrar em equilíbrio. No hidróxido de lítio os tempos foram menores que para o caso do hidróxido de potássio. Já para o caso do etanol não foi observado nenhuma alteração com a variação de eletrólito nem de rotação.

Em ambos os mecanismos propostos existe o processo de auto-catalise. No qual há liberação de sítios superficiais e estão relacionados ao pico de reativação observado nos voltamogramas cíclicos. 


\section{Referências bibliográficas}

1. ANTOLINE, E.; GONZALEZ, ER E. Alkaline Direct Alcohol Fuel Cell. Journal of Power Sources, v. 195, p. 3431-3450, 2005

2. ALCAIDE, F.; ALVAREZ, G.; CABOT, PE.; GRANDE, HJ.; MIGUEL, O.; QUEREJETA, A. Testing of carbon supported Pd-Pt electrocatalysts for methanol eletrooxidation in direct methanol fuel cells. International Journal of Hydrogen Energy, v. 36, p. 4432-4439, 2011

3. CARRETTE, L.; FRIENDRICH, KA.; STIMMING, U. Fuel Cells Fundamentals and Applications. Fuel Cells, v. 1, p.5-39, 2001.

4. ARICO, AS.; SRINIVASAN, S.; ANTONUCCI, V. DMFCs: From Fundamental Aspects to Technology Development. Fuel Cells, v. 1, p. 133-161, 2001.

5. BROUZGOU, A.; PODIAS, A.; TSIAKARAS, P. PEMFCs and AEMFCs directly fed with ethanol: a current status comparative review. Journal of applied Electrochemistry, v. 43, p. 119-136, 2013

6. IWASITA, T.; Electrocatalysis of methanol oxidation. Electrochimica Acta. v. 47, p. $3663-3674,2002$

7. CAMARA, G.A; IWASITA, T.Parallel pathways of ethanol oxidation: The effect of ethanol concentration.Journal of Electroanalytical Chemistry. v. 578 , p. 315-321,2005.

8. GOTZ, M E WENDT, H. Binary And Ternary Anode Catalyst Formulations Including the Elements W, Sn And Mo For Pemfcs Operated on Methanol or Reformate Gas. ELECTROCHIMICA ACTA. v. 43, p. 3637-3644, 1998

9. WASMUS, S E KUVER, A. Methanol Oxidation and Direct Methanol Fuel Cells: A Selective Review. JOURNAL OF ELECTROANALYTICAL CHEMISTRY. v. 461, p. 14-31, 1999.

10. ANTOLINI, E. Formation of carbon-supported PtM alloys for low temperature fuel cells: a review. Materials Chemistry and Physics, v. 78, p. 563-573, 2003

11. CAPON, A.; PARSONS, R. Oxidation of Formic-Acid On Noble-Metal Electrodes .2. Comparison of Behavior of Pure Electrodes. JOURNAL OF ELECTROANALYTICAL CHEMISTRY . v. 44, p. 239-254, 1973 .

12. BIEGLER, T. Composition of Electrosorbed Methanol. JOURNAL OF PHYSICAL CHEMISTRY. v. 72, p. 1571-1578, 1968.

13. TRIPKOVIC, AV.; POPOVIC, KD.; GRGUR, BN.; BLIZANAC, B.; ROSS, PN.; MARKOVIC, NM.Methanol Electrooxidation on Supported Pt and PtRu 
Catalysts In Acid and Alkaline Solutions. ELECTROCHIMICA ACTA . v. 47, p. 3707-3714

14. SUMODJO, PTA, DASILVA, EJ; RABOCKAI, T. Electrosorption Of Hydroxylated Compounds - A Comparative-Study Of Molecules With 3 CarbonAtoms. Journal of Electroanalytical Chemistry. v. 271, p. 305-317, 1989.

15. XU, CW; CHENG, LQ; SHEN, PK; LIU, YL Methanol and ethanol electrooxidation on $\mathrm{Pt}$ and $\mathrm{Pd}$ supported on carbon microspheres in alkaline media. Electrochemistry Communications. v. 9, p. 997-1001, 2007.

16. XU, CW.; LIU, YL.; YUAN, DS. Pt and Pd supported on carbon microspheres for alcohol electrooxidation in alkaline media. International Journal of Electrochemical Science.v2, p. 674-680,2007.

17. CARBONIO, E. A., NAGAO, R.; GONZALEZ, ER.; VARELA, H. Temperature effects on the oscillatory electro-oxidation of methanol on platinum. Physical Chemistry Chemical Physics.v. 11, p. 665-670, 2002.

18. Nagao R.; Epstein,RI.; Gonzalez, ER.; Varela, H. Temperature (Over)Compensation in an Oscillatory Surface Reaction. Journal of Physical. Chemistry. v. 112, p. 4617-4624, 2002 .

19. OLIVEIRA, C. P.; LUSSARI, N. V.; SITTA, E.; VARELA, H. Oscillatory electro-oxidation of glycerol on platinum. Electrochimica Acta. v. 85, p. 674679,2012 .

20. PERINI, N.;SITTA, E.; ANGELO, ACD.; VARELA, H. Electrocatalytic activity under oscillatory regime: The electro-oxidation of formic acid on ordered $\mathrm{Pt}_{3} \mathrm{Sn}$ intermetallic phase. Catalysis Communications.v. 30, p. 23-26,2012.

21. TIAN, M.; CONWAY, BE. Phenomenology of oscillatory electro-oxidation of formic acid at $\mathrm{Pd}$ : role of surface oxide films studied by voltammetry, impedance spectroscopy and nanogravimetry. Jounal of Eletroanalytical of Chemetry, v. 581, p.176-189, 2005.

22. MOTA, A. ; SALMAZO, D. ; VARELA. H. ; GONZALEZ, E. R.; EISWIRTH, $M$. Eletro-oxidação oscilatória de ácido Fórmico sobre Paládio: uma visão cinética e mecanística, Bento Gonçalves, CD XXVIII Sibee, 2011

23. CUI, CF.; SONG, SQ.; SHEN, PK.; KOWAL, A. BIANCHINI, C. Firstprinciples considerations on catalytic activity of $\mathrm{Pd}$ toward ethanol oxidation. Journal of Physical Chemistry, v. 113, p. 15639-15642, 2009

24. TICIANELLI, E.; GONZALEZ, ER. Eletroquimica: princípios e aplicações.São Paulo : Edusp, 2002. 220 p

25. BOCKRIS, JO.; DEVANATHAN, MAV.; MULLER, K. On Structure Of Charged Interfaces. PROCEEDINGS OF THE ROYAL SOCIETY OF LONDON 
SERIES A-MATHEMATICAL AND PHYSICAL SCIENCES. 1356, p. $55-65$, 1963.

26. STRMCNIK, D.; KODAMA, K. VAN DER VLIET, D.; GREELEY, J.; STAMEKOVIC, VR.; MARKONIC, NM. The role of non-covalent interactions in electrocatalytic fuel cell reactions on platinum. Nature Chemistry, v. 1, p. 466476, 2009

27. SITTA, E. BATISTA, BC.; VARELA, H. The Impact Of The Alkali Cation On The Mechanism of The Electro-Oxidation Of Ethylene Glycol on Pt. Chemical Communications. v. 47, p. 3775-3777, 2011.

28. VARELA, H.; SITTA, EF.; BATISTA, B. Handbook of Fuel Cells Fundamentals, Technology and Applications. Harumi Yokokawa: John Wiley \& Sons, 2009. 1-15 p.

29. Batista BC.; Sitta. E.; Eiswirth, M.; Varela, H. Autocatalysis in the open circuit interaction of alcohol molecules with. Physical Chemistry Chemical Physics. v. 10, p. 6686-6692,2008

30. Varela, H.; Sitta, E. On the Open-Circuit Interaction Between Methanol. Journal Solid State Electrochemistry. v. 12, p. 559 - 567, 2008.

31. MANZHOS, RA.; PODLOVCHENKO, BI.; MAKSIMOV, YM. Special Features of Methanol Interaction with Adsorbed Oxygen at Platinized Platinum Electrode: Transients of the Open-Circuit Potential. Russian Journal of Electrochemistry, v. 43, p. 1268-1272, 2007

32. MAKSIMOV, Y.; M. E PODLOVCHENKO, B. I. Mechanism of Interaction of Molecular Hydrogen with Adsorbed Oxygen on Platinum Electrodes under Open Circuit Conditions. Russian Journal of Electrochemistry. v. 45, n. 1, p. 8186,2009

33. PODLOVCHENKO, B. I.; R.A. MANZHOS, R. A.; E MAKSIMOV, Y. M. Interaction of HCO-Substances With Adsorbed Oxygen on Platinum Electrodes: Open-Circuit Transient Reactions of $\mathrm{HCOOH}$ and $\mathrm{CO}$. Electrochimica Acta. $\mathrm{n}$. 50 , p. $4807-4813,2005$.

34. PODLOVCHENKO, B.I,, MANZHOS, R.A. E MAKSIMOV, Y. M. Kinetics and Mechanism of Interaction between Methanol and Adsorbed Oxygen on a Smooth Polycrystalline Platinum Electrode: Transients of the Open-Circuit Potential. Russian Journal of Electrochemistry. v. 4, p 1061 - 1066, 2006.

35. LAIDLER, K. J. Chemical kinetics. New York : Harper \& Row, 1987.

36. MASEL, RI. Chemical kinetics. New York : Wiley, 2001.

37. TAKAMURA, T.; MINAMIYAMA. K. Anodic Oxidation of Methanol at Palladium Electrode in Alkaline Solution. Journal of the electrochemical Society. v 112, n 3, p. 333-335, 1965. 
38. GRDEN, M.; CZERWINSKI, A. EQCM studies on Pd-Ni alloy oxidation in basic solution. Journal of Solid State Electrochemistry, v. 12, p. 375-385, 2008

39. VRACAR, LJ.; BUROJEVIC, S.; KRSTAJIC, N. The surface processes at $\mathrm{Pd}-\mathrm{Ni}$ alloy in acid and alkaline solutions. International Journal of Hydrogen Energy, v. 23, p. 1157-1164, 1998.

40. GRDEN, M.; KOTOWSKI, J.; CZERWINSKI, A. The study of electrochemical palladium behavior using the quartz crystal microbalance: II. Basic solution. Journal of Solid State Electrochemistry, v. 4, p. 273-278, 2000

41. MELLINGER, ZJ.; KELLY, TG.; CHEN, JG. Pd-modified tungsten carbide for methanol electro-oxidation: from surface science studies to electrochemical evaluation. ACS Catalsys, v. 2, p.751-758, 2012

42. ZHANG, AJ.; BIRSS, VI.; VANYSEK, P. Impedance characterization formed palladium of thin electrochemically oxide films. Journal of Electroanalytical Chemistry, v. 378, p 63-76, 1994.

43. BIRSS, VI.; GLOEDZINOWSKI, M. The unusual reduction behavior of Thin, hydrous platinum oxide-films. Journal of Electroanalytical Chemistry, v. 351, p. $227-243,1993$

44. BURKE, LD.; ROCHE, MBC. An Electrochemical Investigation of monolayer and multilayer oxide films on palladium in aqueous media. Journal of Electroanalytical Chemistry, v. 186, p. 139 -154, 1985.

45. BOLZAN, AE.; ARVIA, AJ. The electrochemical behaviour of hydrous palladium oxide layers formed at high positive potentials in different electrolyte solutions. Journal of Electroanalytical Chemistry. v. 322, p. $247-265,1992$.

46. TILAK, B.V.; CONWAY B.E. Overpotential decay behavior complex electrode reactions involving adsorption. Electrochimica Acta., v. 21, n. 10, p. 745- 752,1976

47. CHIERCHIE, T.; MAYER, C.; LORENZ, WJ. Structural-Changes of Surface Oxide Layers on Palladium. Journal Electroanalytical Chemistry, v. 135, p. 211-220, 1982

48. BOLZAN, AE.; ZERBINO, JO.; MACCHI, E.; ARVIA, AJ. Ellipsometry and electron-diffraction study of anodically formed pd oxide layers. Thin Solid Films, v. 233, p. 77-81, 1993..

49. ZHANG, AJ.; BIRSS, VI.; VANYSEK, P. Impedance characterization formed palladium of thin electrochemically oxide films. Journal of Electroanalytical Chemistry, v. 378, p 63-76, 1994 
50. BURKE, LD.; CASEY, JK. An examination of the electrochemical-behavior of palladium in base. Journal of the Electrochemical Society, v.140, p 12921298, 1993

51. HU, CC.; WEN, TC. Voltammetric investigation of palladium oxides .1. their formation/reduction in $\mathrm{NaOH}$. Electrochimica Acta,v. 40, p 495- 503, 1995.

52. POURBAIX, M.Atlas of Electrochemical Equilibria in Aqueous Solutions. Oxford : Pergamon Press, 1966. 644 p.

53. KIM, KS.; GOSSMANN, AF.; WINOGRAD, N. X-ray photoelectron spectroscopic studies of palladium oxides and palladium-oxygen electrode. Analytical Chemistry, v. 46, p. 197-200, 1974

54. ZHANG, AJ.; GAUR, M.; BIRSS, VI. Growth of thin, hydrous oxide-films at pd electrodes. Journal of Electroanalytical Chemistry, v. 389, p. 149-159, 1995.

55. NISHIMURA, K.; KUNIMATSU, K.; ENYO, M. Electrocatalysis on Pd + Au alloy electrodes .3. IR spectroscopic studies on the surface species derived from $\mathrm{CO}$ and $\mathrm{CH}_{3} \mathrm{OH}$ in $\mathrm{NaOH}$ solution. Journal of Electroanalytical Chemistry. v $1, \mathrm{p} 167-179,1989$

56. YANG, YY.; REN, J.; ZHANG, HX.; ZHOU, ZY.; SUN, SG.; CAI, WB. Infrared Spectroelectrochemical Study of Dissociation and Oxidation of Methanol at a Palladium Electrode in Alkaline Solution. Langmuir, v. 29, p 1709-1716, 2013.

57. FANG, X.; WANG, LQ.; SHEN, PK.; CUI, GF.; BIANCHINI, C. An in situ Fourier transform infrared spectroelectrochemical study on ethanol electrooxidation on Pd in alkaline solution. Journal of Power Sources, v. 195, p. 1375-1378, 2010.

58. GUO, WY.; LI, M.; LU, XQ.; XHU, HY.; LI. Y.; LI, SR.; ZHAOm LM. Ethanol decomposition on a $\operatorname{Pd}(110)$ surface: a density functional theory investigation. Dalton Transactions. v. 42, p. 2309-2018, 2013.

59. JERKIEWICZ, G. Hydrogen sorption at/in electrodes. Progress in Surface Science. v. 57, p. 137-186,1998.

60. JERKIEWICZ, G.; ZOLFAGHARI, A. Comparison of Hydrogen Electroadsorption From the Electrolyte With Hydrogen Adsorption From the Gas Phase. Journal of The Electrochemical Society. v. 143, p. 1240-1248, 1996.

61. RAND, DAJ.; WOODS, R. Nature of Adsorbed Oxygen on Rhodium, Palladium And Gold Electrodes. Journal of Electroanalytical Chemistry. v. 31, p. 29-35, 1971. 
62. BREITER, MW. Dissolution and Adsorption of Hydrogen at Smooth Pd Wires At Potentials of Alpha Phase in Sulfuric-Acid Solution. Journal of Electroanalytical Chemistry. v. 81, p. 275-284, 1977.

63. CORREIA, AN.; MASCARO, LH.; MACHADO, SAS.; AVACA, LA Active Surface Area Determination of $\mathrm{Pd}$-Si Alloys by $\mathrm{H}$-Adsorption. Electrochimica Acta. v. 42,p. 493-495,1997.

64. NAOHARA, H., YE, S.; UOSOKI, K. Thickness dependent electrochemical reactivity of epitaxially electrodeposited palladium thin layers on $\mathrm{Au}(111)$ and $\mathrm{Au}(100)$ surfaces. Journal of Electroanalytical Chemistry. v. 500, p 435 445, 2001.

65. SITTA, E.; NASCIMENTO, MA.; VARELA, H. Complex kinetics, high frequency oscillations and temperature compensation in the electro-oxidation of ethylene glycol on platinum. Physical Chemistry Chemical Physics. v. 12, p. 15195-15206, 2010

66. BATISTA, BC.; VARELA, H. Open Circuit Interaction of Formic Acid with Oxidized Pt Surfaces: Experiments,. Journal of Physical Chemistry ,. , v. 114, p. 18494-18500, 2010.

67. IWASITA. T. Handbook of fuel cells - fundamentals and technology Chichester, : Vielstich W, Gasteiger HA, Lamm A, 2003,603p.. 


\section{Anexos}

Curriculum Vitae

Pessoal

Nome: $\quad$ Debora Heloisa Capella Salmazo

Nascimento 02 de setembro de 1987, Rio Claro - SP, Brasil

Filiação Urbano Salmazo e Emília Aparecida Capella Salmazo

Formação Acadêmica

Bacharel em Química ( Énfase em Gestão Qualidade)
Universidade de São Paulo, São Paulo, Brasil
Título: Influência da constante de velocidade de
envenenamento nas instabilidades dinâmicas do etileno
glicol
Orientador: Prof. Dr. Hamilton Varela
Bolsista: Pró Reitoria de Graduação

Mestre em Ciências ( Ênfase em Físico-Química )
Universidade de São Paulo, São Paulo, Brasil
Titulo: Sobre a interação em circuito aberto entre metanol
ou etanol e superfícies oxidadas de paládio
Orientador: Prof. Dr. Hamilton Varela
Bolsista: Conselho Nacional de Desenvolvimento Científico
e Tecnológico.


MOTA, A. ;SALMAZO, D. H. C.; VARELA, HAMILTON ; GONZALES, E. R ; EISWIRTH, M . Eletro-oxidação oscilatória de ácido fórmico sobre Paládio: uma visão cinética e mecanística. In: XVIII Simpósio Brasileiro de Eletroquímica e Eletroanalítica, 2011, Bento Gonçalves. (expandido)

SALMAZO, D. H. C.; PERINI, N. ; VARELA, HAMILTON . Interação entre o metanol e a superfície de paládio oxidada sob condição de circuito aberto. 2013. In: XIX Simpósio Brasileiro de Eletroquímica e Eletroanalítica, 2013, Campos do Jordão.

SALMAZO, D. H. C.; SITTA, E. F. ; VARELA, HAMILTON . Influência da constante de velocidade de envenenamento nas instabilidades dinâmicas do etileno glicol. 2012. In: XX Congresso da Sociedade Ibero Americana de Eletroquímica, Fortaleza.

SALMAZO, D. H. C. ; MOTA, A. ; VARELA, HAMILTON . Instabilidades cinéticas na reação de eletrooxidação de ácido fórmico sobre paládio. 2010. In : XVIII Congresso de Iniciação Cientifica, São Carlos.

\section{Apresentações Orais em Conferências Científicas}

SALMAZO, D. H. C.; SITTA, E. F. ; VARELA, HAMILTON . Influência da constante de velocidade de envenenamento nas instabilidades dinâmicas do etileno glicol. 2012. In: XX Congresso da Sociedade Ibero Americana de Eletroquímica, Fortaleza.

SALMAZO, D. H. C.; MOTA, A. ; VARELA, HAMILTON . Instabilidades cinéticas na reação de eletrooxidação de ácido fórmico sobre paládio. 2010. In : XVIII Congresso de Iniciação Cientifica, São Carlos. 